\title{
Characterization of Inositol Phosphorylceramides from Leishmania major by Tandem Mass Spectrometry with Electrospray Ionization
}

\author{
Fong-Fu Hsu, ${ }^{a}$ John Turk, ${ }^{a}$ Kai Zhang, ${ }^{* b}$ and Stephen M. Beverley ${ }^{\mathrm{b}}$ \\ ${ }^{a}$ Mass Spectrometry Resource, Division of Endocrinology, Diabetes, Metabolism, and Lipid Research, \\ Department of Internal Medicine, Washington University School of Medicine, St. Louis, Missouri, USA \\ ${ }^{b}$ Department of Molecular Microbiology, Washington University School of Medicine, St. Louis, Missouri, \\ USA
}

\begin{abstract}
We describe tandem mass spectrometric approaches, including multiple stage ion-trap and source collisionally activated dissociation (CAD) tandem mass spectrometry with electrospray ionization (ESI) to characterize inositol phosphorylceramide (IPC) species seen as [M- $\mathrm{H}]^{-}$and $\left[\mathrm{M}-2 \mathrm{H}+\mathrm{Li}^{-}\right.$ions in the negative-ion mode as well as $[\mathrm{M}+\mathrm{H}]^{+},[\mathrm{M}+\mathrm{Li}]^{+}$, and $[\mathrm{M}-\mathrm{H}+$ $2 \mathrm{Li}]^{+}$ions in the positive-ion mode. Following CAD in an ion-trap or a triple-stage quadrupole instrument, the $[\mathrm{M}-\mathrm{H}]^{-}$ions of IPC yielded fragment ions reflecting only the inositol and the fatty acyl substituent of the molecule. In contrast, the mass spectra from $\mathrm{MS}^{3}$ of $[\mathrm{M}-\mathrm{H}-$ Inositol] $]^{-}$ions contained abundant ions that are readily applicable for assignment of the fatty acid and long-chain base (LCB) moieties. Both the product-ion spectra from $\mathrm{MS}^{2}$ and $\mathrm{MS}^{3}$ of the $[\mathrm{M}-2 \mathrm{H}+\mathrm{Alk}]^{-},[\mathrm{M}+\mathrm{H}]^{+},[\mathrm{M}+\mathrm{Alk}]^{+}$, and $[\mathrm{M}-\mathrm{H}+2 \mathrm{Alk}]^{+}$ions also contained rich fragment ions informative for unambiguous assignment of the fatty acyl substituent and the LCB. However, the sensitivity of the ions observed in the forms of $[\mathrm{M}-2 \mathrm{H}+\mathrm{Alk}]^{-},[\mathrm{M}+\mathrm{H}]^{+}$, $[\mathrm{M}+\mathrm{Alk}]^{+}$, and $[\mathrm{M}-\mathrm{H}+2 \mathrm{Alk}]^{+}(\mathrm{Alk}=\mathrm{Li}, \mathrm{Na})$ is nearly 10 times less than that observed in the $[\mathrm{M}-\mathrm{H}]^{-}$form. In addition to the major fragmentation pathways leading to elimination of the inositol or inositol monophosphate moiety, several structurally informative ions resulting from rearrangement processes were observed. The fragmentation processes are similar to those previously reported for ceramides. While the tandem mass spectrometric approach using $\operatorname{MS}^{n}(n=2,3)$ permits the structures of the Leishmania major IPCs consisting of two isomeric structures to be unveiled in detail, tandem mass spectra from constant neutral loss scans may provide a simple method for detecting IPC in mixtures. (J Am Soc Mass Spectrom 2007, 18, 1591-1604) (c 2007 American Society for Mass Spectrometry
\end{abstract}

I nositol phosphorylceramide (IPC) consists of a ceramide moiety, to which an inositol phosphate residue is linked via the 1-OH of the long-chain base (LCB) (see IPC structure in Schemes). The identification of IPCs in the membrane of Saccharomyces cerevisiae was first reported by Smith and Lester [1]. However, the glycosylated IPC (glycosylinositol phosphorylceramides or GIPCs) was first found in the membrane of Saccharomyces cerevisiae and Candida utilis by Wagner and Zofcsik, earlier [2]. In plants, GIPCs also constitute an abundant group of membrane sphingolipids [3, 4]. Different from plants and fungi, the primary sphingolipid species in Leishmania spp. and Trypanosoma spp. is unglycosylated IPC [5-7], which accounts for $5 \%$ to $10 \%$

Address reprint requests to Dr. Fong-Fu Hsu, Box 8127, Washington University School of Medicine, 660 S. Euclid, St. Louis, MO 63110, USA. E-mail: fhsu@im.wustl.edu

* Current address: Department of Biological Sciences, Texas Tech University, Lubbock, TX 79409, USA. of total cellular lipids in Leishmania [5] and are enriched in raft-associated membrane fractions [8].

IPC is synthesized through the transfer of inositol phosphate from phosphatidylinositol to the 1-OH group of ceramide or phytoceramide $[9,10]$. This transfer reaction is catalyzed by the phosphatidylinositol: ceramide phosphoinositol transferase (IPC synthase), a membrane-bound enzyme $[11,12]$. In $S$. cerevisiae and $C$. albicans, phytoceramide is the preferred receptor for phosphoinositol. These fungi synthesize a family of sphingolipids (SLs) composed of unglycosylated IPC, mannose inositol phosphoceramide (MIPC), and mannose di-inositol phosphoceramide $\left(\mathrm{M}[\mathrm{IP}]_{2} \mathrm{C}\right)$ [11, 13]. Available evidence indicates that AUR1, an essential gene, encodes the IPC synthase or a subunit of the enzyme in S. cerevisiae [14]. In contrast to fungi and plants, mammalian cells do not synthesize IPC or GIPCs; instead, choline phosphate is transferred from phosphatidylcholine to the 1-OH group of ceramide, leading to the synthesis of sphingomyelin (SM). This 
difference in SL metabolism between mammalian cells and fungi represents an attractive target for antifungal drugs such as khafrefungin [15] and aureobasidin A [14, 16], which specifically inhibit the IPC synthase.

In addition to being membrane component, IPC species regulate virulence in pathogenic fungi. In Cryptococcus neoformans, IPC-derived diacylglycerol induces the transcription of virulence factor App1, which inhibits phagocytosis by alveolar macrophages [17], as well as activating protein kinase $\mathrm{C} 1$, which promotes cellwall stability and melanin production in C. neoformans [18]. Recent work indicates Leishmania parasites synthesize high levels of IPC as both promastigotes (the stage residing extracellularly in the midgut of sandfly vectors) and amastigotes (the stage residing intracellularly within phagolysosomes of mammalian macrophages), suggesting this lipid plays important roles in both stages [19-21]. Mutants defective in the synthesis of sphingoid bases (via inactivation of serine palmitoyltransferase; spt2) or degradation of sphingosine-1phosphate (via inactivation of sphingosine-1-phosphate lyase; $s p l^{-}$) exhibited severe defects in vesicular trafficking upon entry into stationary phase and failed to differentiate to infective metacyclic form, suggesting sphingolipid metabolism is crucial for the virulence of Leishmania parasites [19, 21, 22]. Remarkably, both mutants were rescued by ethanolamine, a downstream metabolite of the de novo SL pathway, a finding with profound implications to role of SLs in the promastigote stage [22]. However, despite disruptions in the de novo synthesis of SLs, spt2- amastigotes retain high levels of IPC, suggesting that this stage salvages one or more IPC precursors from the mammalian host for conversion into the parasite specific IPC [20]. In this regard, the SL mutant amastigotes resemble WT amastigotes, which normally down-regulate the de novo SL and SPL (sphingosine-1-phosphate lyase)-dependent ethanolamine synthetic pathways [19, 21, 22]. Genetic analysis of the role of amastigote IPC thus awaits the development of parasite mutants deficient in IPC synthesis and/or SL salvage from the host.

The structure of IPC is well established. Tandem sector mass spectrometric approach to characterize Leishmania Mexicana IPC as the $[\mathrm{M}+\mathrm{H}]^{+}$ions desorbed by FAB was previously described by Singh et al. [23]. Levery et al. also described tandem mass spectrometric approaches to characterize glycosylinositol phosphorylceramides (GIPCs), the complex derivatives of IPC, using the lithiated adduct ions desorbed by ESI in the positive-ion mode [24-26]. IPC species from Trypanosomatids (Leishmania spp. and Trypanosoma spp.) have been previously analyzed by ESI tandem mass spectrometry in the negative-ion mode $[6,7,19]$. Here we report more detailed structural studies towards the identification of the long-chain base and the fatty acid substituent of IPC using tandem mass spectrometry. ESI tandem quadrupole and ion-trap mass spectrometric approaches are used to characterize the IPC species in the promastigote stage of L. major, a pathogen re- sponsible for cutaneous leishmaniasis. These approaches afford the structures of IPC species in the forms of $[\mathrm{M}-\mathrm{H}]^{-}$and $[\mathrm{M}-2 \mathrm{H}+\mathrm{Li}]^{-}$ions in the negative-ion mode, as well as in the forms of $[\mathrm{M}+\mathrm{H}]^{+}$, $[\mathrm{M}+\mathrm{Li}]^{+}$, and $[\mathrm{M}-\mathrm{H}+2 \mathrm{Li}]^{+}$ions in the positive-ion mode to be unveiled in detail. The mechanisms underlying the fragmentation processes of IPC revealed by tandem mass spectrometry will be presented.

\section{Materials}

All chemicals used are in spectroscopic grade and were purchased from Sigma Chemical Co. (St. Louis, MO). Total lipids were extracted from L. major as previously described [19]. ${ }^{\circ}$ Briefly, ${ }^{\circ}$ wild ${ }^{\circ}$ type $^{\circ}$ L. major LV39 ${ }^{\circ}$ clone 5 (Rho/SU/59/P) cells were grown in M199 medium with supplements and $10 \%$ heat inactivated fetal bovine serum at $26^{\circ} \mathrm{C}$. Cells were harvested, washed and resuspended in phosphate buffered saline (PBS, 137 $\mathrm{mM} \mathrm{NaCl}, 10 \mathrm{mM}$ Phosphate, $2.7 \mathrm{mM} \mathrm{KCl}, \mathrm{pH} 7.4)$ at 2 $\times 10^{8}$ cells $/ \mathrm{mL}$, followed by sonication on ice $(15 \mathrm{~W}$, $5 \mathrm{~s})$. Afterwards lysates were extracted with $3.75 \mathrm{vol}$ of $\mathrm{CHCl}_{3} /$ methanol (1:2), followed by 1.25 vol of $\mathrm{CHCl}_{3}$, and 1.25 vol of water. After centrifugation $(1000 g, 10$ min), the upper aqueous phase was removed and the organic phase was washed once with water. The organic phase was then dried under nitrogen and dissolved in $\mathrm{CHCl}_{3} /$ methanol (1:2) at the equivalent of $2 \times$ $10^{9}$ cells $/ \mathrm{ml}$ and stored at $-20^{\circ} \mathrm{C}$.

\section{Methods}

\section{Mass spectrometry}

Low-energy CAD tandem mass spectrometry experiments were conducted both on a Finnigan (San Jose, CA) LCQ DECA ion-trap (IT) mass spectrometer (MS) with the Xcalibur operating system and a Finnigan TSQ-7000 triple-stage quadrupole (TSQ) mass spectrometer with ICIS operating system. Lipid extract was infused ( $3 \mu \mathrm{L} / \mathrm{min}$ ) to the ESI source, where the skimmer was set at ground potential, the electrospray needle was set at $4.5 \mathrm{kV}$, and temperature of the heated capillary was $260{ }^{\circ} \mathrm{C}$. The automatic gain control of the ion trap was set to $5 \times 10^{7}$, with a maximum injection time of $400 \mathrm{~ms}$. Helium was used as the buffer and collision gas at a pressure of $1 \times 10^{-3}$ mbar $(0.75$ mTorr). The $\mathrm{MS}^{\mathrm{n}}$ experiments were carried out with a relative collision energy ranging from $30 \%$ to $40 \%$ and with an activation $q$ value at 0.25 . The activation time was set at $100 \mathrm{~ms}$. Mass spectra were accumulated in the profile mode, typically for 3 to $5 \mathrm{~min}$ for $\mathrm{MS}^{2}$ - and $\mathrm{MS}^{3}$-spectra. The mass resolution of the instrument was tuned to $0.6 \mathrm{Da}$ at half peak height.

For product-ion spectra obtained with a triple quadrupole instrument, the precursor ions were selected in the first quadrupole (Q1), collided with Ar (2.3 mTorr) in the rf-only second quadrupole (Q2) and analyzed in the third quadrupole (Q3). The collision energies were 
Table 1. Composition of IPC from Leishmania major ${ }^{\text {a }}$

\begin{tabular}{|c|c|c|c|c|c|c|c|c|c|}
\hline$[\mathrm{M}-\mathrm{H}]^{-}$ & $\begin{array}{l}{[\mathrm{M}-2 \mathrm{H}} \\
+\mathrm{Li}]^{-}\end{array}$ & $\begin{array}{l}{[\mathrm{M}-2 \mathrm{H}} \\
+\mathrm{Na}]^{-}\end{array}$ & {$[\mathrm{M}+\mathrm{H}]^{+}$} & {$[\mathrm{M}+\mathrm{Li}]^{+}$} & {$[\mathrm{M}+\mathrm{Na}]^{+}$} & $\begin{array}{c}{[\mathrm{M}-\mathrm{H}+} \\
2 \mathrm{Li}]^{+}\end{array}$ & $\begin{array}{c}{[\mathrm{M}-\mathrm{H}+} \\
2 \mathrm{Na}]^{+}\end{array}$ & Structure & $\begin{array}{c}\text { Relative } \\
\text { abundance } \\
\text { (\% of base peak) }\end{array}$ \\
\hline 750.6 & *756.6 & *772.6 & 752.6 & *758.6 & *774.6 & *764.6 & *796.6 & $\begin{array}{l}\text { d14:1/18:0-IPC } \\
\& \text { d16:1/16:0-IPC }\end{array}$ & 1 \\
\hline 764.6 & *770.6 & *786.6 & 766.6 & *772.6 & *788.6 & *778.6 & *810.6 & $\begin{array}{l}\text { d16:1/17:0-IPC } \\
\text { \& d15:1/18:0-IPC }\end{array}$ & 1 \\
\hline 776.6 & *782.6 & *798.6 & 778.6 & *784.6 & *800.6 & *790.6 & *822.6 & d16:1/18:1-IPC & 1 \\
\hline 778.6 & 784.6 & 800.6 & 780.6 & 786.6 & 802.6 & 792.6 & 824.6 & d16:1/18:0-IPC & 100 \\
\hline 792.6 & 798.6 & 804.6 & 794.6 & *800.6 & *816.6 & *806.6 & *832.6 & $\begin{array}{l}\text { d17:1/18:0-IPC } \\
\& \text { d16:1/19:0-IPC }\end{array}$ & 2 \\
\hline 796.6 & 802.6 & 818.6 & 798.6 & 804.6 & 820.6 & 810.6 & *842.6 & t16:0/18:0-IPC & 10 \\
\hline 804.6 & *810.6 & *826.6 & 806.6 & *812.6 & *828.6 & *818.6 & *850.6 & d18:2/18:0-IPC & 1 \\
\hline 806.6 & 812.6 & *828.6 & 808.6 & 814.6 & 830.6 & *820.6 & *852.6 & d18:1/18:0-IPC & 9 \\
\hline 820.6 & *826.6 & *842.6 & 822.6 & *828.6 & *844.6 & *834.6 & *866.6 & $\begin{array}{l}\text { d19:1/18:0-IPC } \\
\text { \& d18:1/19:0-IPC }\end{array}$ & 1 \\
\hline 822.6 & *828.6 & *844.6 & 824.6 & *830.6 & *846.6 & *836.6 & *868.6 & d19:0/18:0-IPC & 1 \\
\hline
\end{tabular}

aData are derived from product-ion analysis with IT and TSO mass spectrometers.

*Not studied.

set at 32 to $45 \mathrm{eV}$. Both Q1 and Q3 were tuned to unit mass resolution and scanned at a rate of $3 \mathrm{~s} / \mathrm{scan}$. The mass spectra were accumulated in the profile mode, typically for 5 to $10 \mathrm{~min}$ for a tandem mass spectrum. For source collisionally activated dissociation (CAD) product-ion spectra, the skimmer voltage was set $40 \mathrm{eV}$ to yield product ions that were selected for further MS/MS.

\section{Nomenclature}

The nomenclature previously described for sphingomyelin and ceramide was used [27-29]. Therefore, the designation of, for example, d18:1/16:0-IPC signifies the IPC consists of a sphingosine-LCB and a palmitoyl (16:0-fatty acyl) substituent; while t16:0/18:0-IPC signifies that IPC contains a 16:0-phytosphingosine LCB and a stearoyl moiety.

\section{Results and Discussion}

IPC yielded abundant $[\mathrm{M}-\mathrm{H}]^{-}$ions, when subjected to ESI in the negative-ion mode. In the presence of alkali metal ion $\left(\mathrm{Alk}^{+}, \mathrm{Alk}=\mathrm{Li}, \mathrm{Na}, 1 \mathrm{~nm} / \mathrm{uL}\right), \mathrm{IPC}$ also yielded $[\mathrm{M}-2 \mathrm{H}+\mathrm{Alk}]^{-}$ions in the negative-ion mode, as well as the $[\mathrm{M}+\mathrm{Alk}]^{+}$and $[\mathrm{M}-\mathrm{H}+2 \mathrm{Alk}]^{+}$ions in the positive ion mode. To obtain the $[\mathrm{M}+\mathrm{H}]^{+}$ion, methanolic solution of $\mathrm{NH}_{4} \mathrm{OAc}$ was added to a final concentration of $1 \mathrm{~nm} / \mathrm{uL}$. In general, the sensitivity observed as the $[\mathrm{M}-\mathrm{H}]^{-}$ion is at least 10 times higher than that observed as the $[\mathrm{M}+\mathrm{Li}]^{+},[\mathrm{M}-\mathrm{H}+2 \mathrm{Li}]^{+},[\mathrm{M}$ $+\mathrm{H}]^{+}$, and $[\mathrm{M}-2 \mathrm{H}+\mathrm{Li}]^{-}$ions. This may be attributable to the fact that IPC possesses a phosphate residue that is readily ionizable. The structures of the Leishmania major IPC deduced from the tandem mass spectra of the various molecular species in this study are listed in Table 1.
Structural Characterization with the $[\mathrm{M}-\mathrm{H}]^{-}$ Ions

The ESI-MS profile of the $[\mathrm{M}-\mathrm{H}]^{-}$ions of IPC isolated from Leishmania major is shown in Figure 1a, which contains major ions at $m / z$ 778, 780, 796, and 806, consistent with the results previously reported by Zhang et al. [20]. The $\mathrm{MS}^{2}$ spectra of the ion at $m / z 778$ obtained with an ITMS (Figure 2a) and a TSQ (Figure $2 b$ ) instruments are nearly identical. The phosphoinositol residue of the molecule is seen by the presence of the prominent ions at $\mathrm{m} / \mathrm{z} 241$, corresponding to a inositol1,2-cyclic phosphate anion, and at $\mathrm{m} / \mathrm{z} 259$ corresponding to a inositol monophosphate anion, along with the ion at $m / z 223$ arising from $m / z 241$ by further loss of $\mathrm{H}_{2} \mathrm{O}$. These ions are characteristic to molecules of inositol phosphorylceramides [7], and are similar to those observed for phosphatidylinositol [30]. The spectrum also contains the ions at $m / z 616(778-162)$ and 598 (778 - 180), arising from losses of a dehydrated inositol and a inositol residues, respectively, as well as the ion at $m / z 512(778-266)$, corresponding to loss of a 18:0-fatty acyl substituent as a ketene (Scheme 1a). The presence of the ion at $\mathrm{m} / \mathrm{z} 512$ suggested that the molecule is a d16:1/18:0-IPC rather than a d18:1/16:0IPC structure as previously reported by Serrano et al. [7]. The structural assignment is further supported by the IT MS ${ }^{3}$ spectrum of the ion at $m / z 598(778 \rightarrow 598$, Figure 2c), which contains ions at $m / z 332$ (598 - 266) corresponding to loss of an 18:0-fatty acyl ketene and at $m / z 314\left(332-\mathrm{H}_{2} \mathrm{O}\right)$ from further loss of $\mathrm{H}_{2} \mathrm{O}$. The spectrum also contains the ion at $m / z$ 388, arising from loss of the d16:1-LCB as an aldehyde and the ion at $\mathrm{m} / \mathrm{z}$ 386, arising from the simultaneous losses of the aldehyde and $\mathrm{H}_{2}$ residues (Scheme 1a, Routes $a$ and $b$ ) [31]. The 18:0-fatty acyl substituent is recognized by the presence of the ion at $m / z 283$, which probably arises 


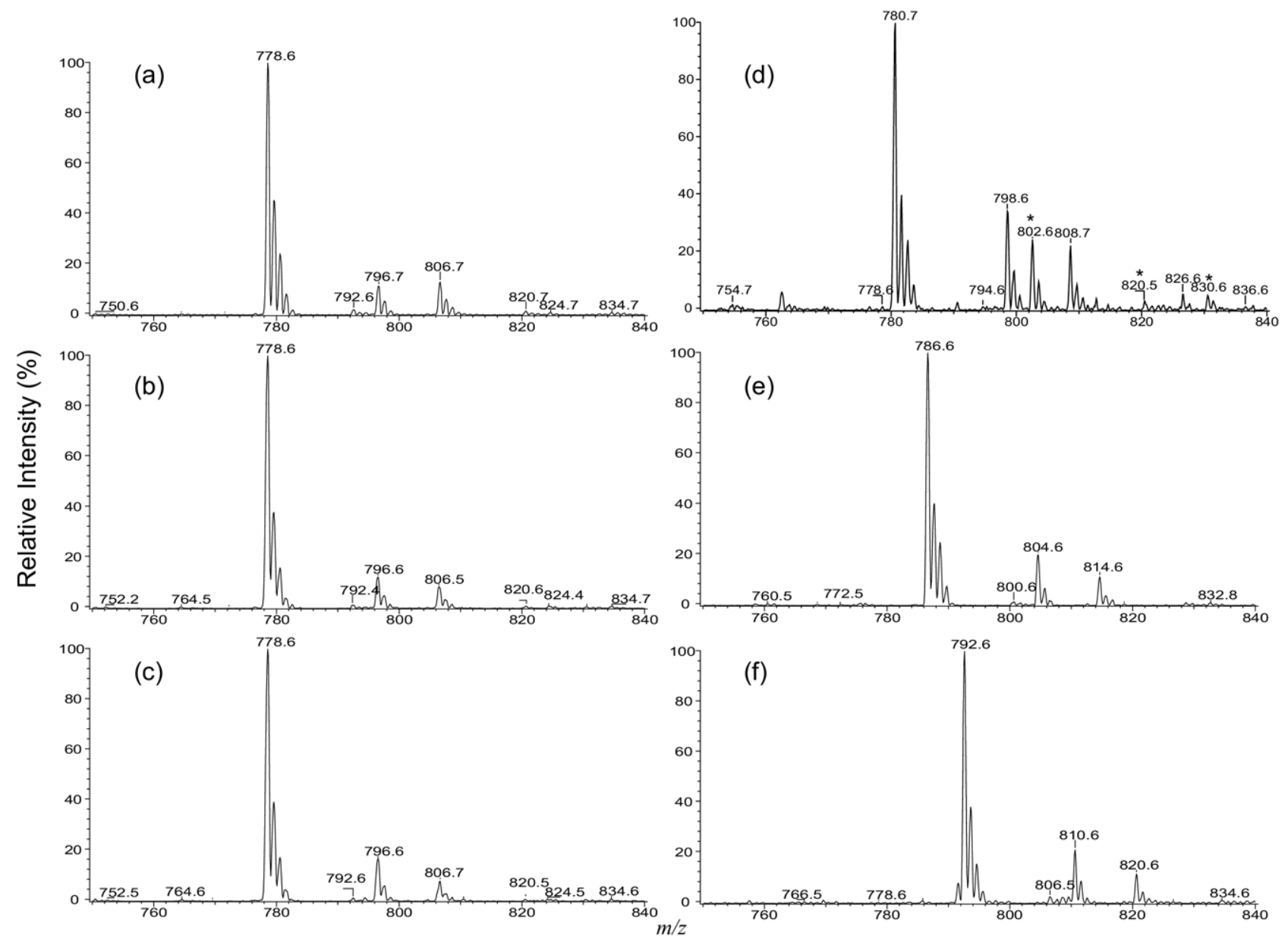

Figure 1. (a) The ESI/MS spectrum of the $[\mathrm{M}-\mathrm{H}]^{-}$ion of IPC extract from Leishmania major, and the MS $^{2}$ spectra of the same extract obtained by precursor-ion scans of 241 (b), of 259 (c), by neutral loss scans of $260(\mathbf{d})$, of $266(\mathbf{e})$, and of $248(\mathbf{f})$ that detect IPCs as the $[\mathrm{M}-\mathrm{H}]^{-}(\mathbf{b}),[\mathrm{M}-\mathrm{H}]^{-}(\mathbf{c}),[\mathrm{M}+\mathrm{H}]^{+}$ $(\mathbf{d}),[\mathrm{M}+\mathrm{Li}]^{+}(\mathbf{e})$, and the $[\mathrm{M}-\mathrm{H}+2 \mathrm{Li}]^{+}(\mathbf{f})$ species, respectively. The ions labeled with an asterisk in $(\mathrm{d})$ are the corresponding $[\mathrm{M}+\mathrm{Na}]^{+}$ions.

from the pathway involving a rearrangement process (Scheme 1a, Route $c$ ) and represents a 18:0-carboxylate anion. This unique formation of carboxylate anion was previously observed for ceramides [31] and provides information for assignment of the fatty acyl substituent. Similarly, the IT MS ${ }^{2}$ product-ion spectrum of the ion at $\mathrm{m} / \mathrm{z} 806$ (Figure 2d) contains the common ions at $\mathrm{m} / \mathrm{z}$ $259,241,223,644(806-162)$ and $626(644-180)$ seen for an IPC, along with the ion at $m / z 540$, corresponding to loss of a 18:0-fatty acyl ketene, suggesting the compound is a d18:1/18:0-IPC. This structural assignment is further confirmed by the IT $\mathrm{MS}^{3}$ spectrum of the ion at $m / z 626$ (806 $\rightarrow 626$, Figure 2e), in which the prominent ions at $\mathrm{m} / \mathrm{z} 360(626-266)$ from loss of the 18:0-fatty acyl ketene and at $m / z 342\left(360-\mathrm{H}_{2} \mathrm{O}\right)$ from further loss of $\mathrm{H}_{2} \mathrm{O}$, along with the ion at $\mathrm{m} / \mathrm{z} 283$, representing a 18:0-carboxylate anion are present. The spectrum also contains the analogous ions at $m / z 388$ and 366 arising from the similar losses of the d18:1-LCB as described earlier, consistent with the assigned d18:1/18:0-IPC structure.
In Figure $2 \mathrm{f}$, the IT $\mathrm{MS}^{2}$ spectrum of $\mathrm{m} / \mathrm{z} 796$ also contains the ion at $\mathrm{m} / \mathrm{z} 530$, arising from loss of a 18:0-fatty acyl ketene, along with the ions at $\mathrm{m} / \mathrm{z} 259$, 241, 223, $634(796-162)$, and $616(796-180)$ that are characteristic to IPC. However, the ion at $m / z 616$ ([M $\mathrm{H}-180]^{-}$) is more abundant than the ion at $\mathrm{m} / \mathrm{z} 634$ ([M $\left.-\mathrm{H}-162]^{-}\right)$. By contrast, the abundances of the analogous ions at $m / z 598\left([\mathrm{M}-\mathrm{H}-180]^{-}\right)$and $616([\mathrm{M}-\mathrm{H}-$ $162]^{-}$) observed in Figure 2a and $\mathrm{b}$ and of the ions at $\mathrm{m} / \mathrm{z}$ $626\left([\mathrm{M}-\mathrm{H}-180]^{-}\right)$and $644\left([\mathrm{M}-\mathrm{H}-162]^{-}\right)$observed in Figure $2 \mathrm{~d}$ are nearly of equal abundance. These differences in the abundances of the $[\mathrm{M}-\mathrm{H}-162]^{-}$and the $[\mathrm{M}-\mathrm{H}-180]^{-}$ions indicate that the $\mathrm{m} / \mathrm{z} 796$ ion may consist of a phytosphingosine LCB rather than a sphingosine LCB. This notion is further revealed by the $\mathrm{MS}^{3}$ spectrum of the ion at $m / z 616(796 \rightarrow 616$, Figure $2 \mathrm{~g})$, in which the ions at $m / z 418$, arising from elimination of a tridecaldehyde (198 Da) residue by cleavage of the 3,4-dihydroxy bond (Scheme $\mathbf{1 b}$, Route $a$ ) and at $m / z 388$ by loss of a 2-hydroxy-tetradecaldehyde (Scheme 1b, Route $b$ ) are present. The spectrum is also dominated by 

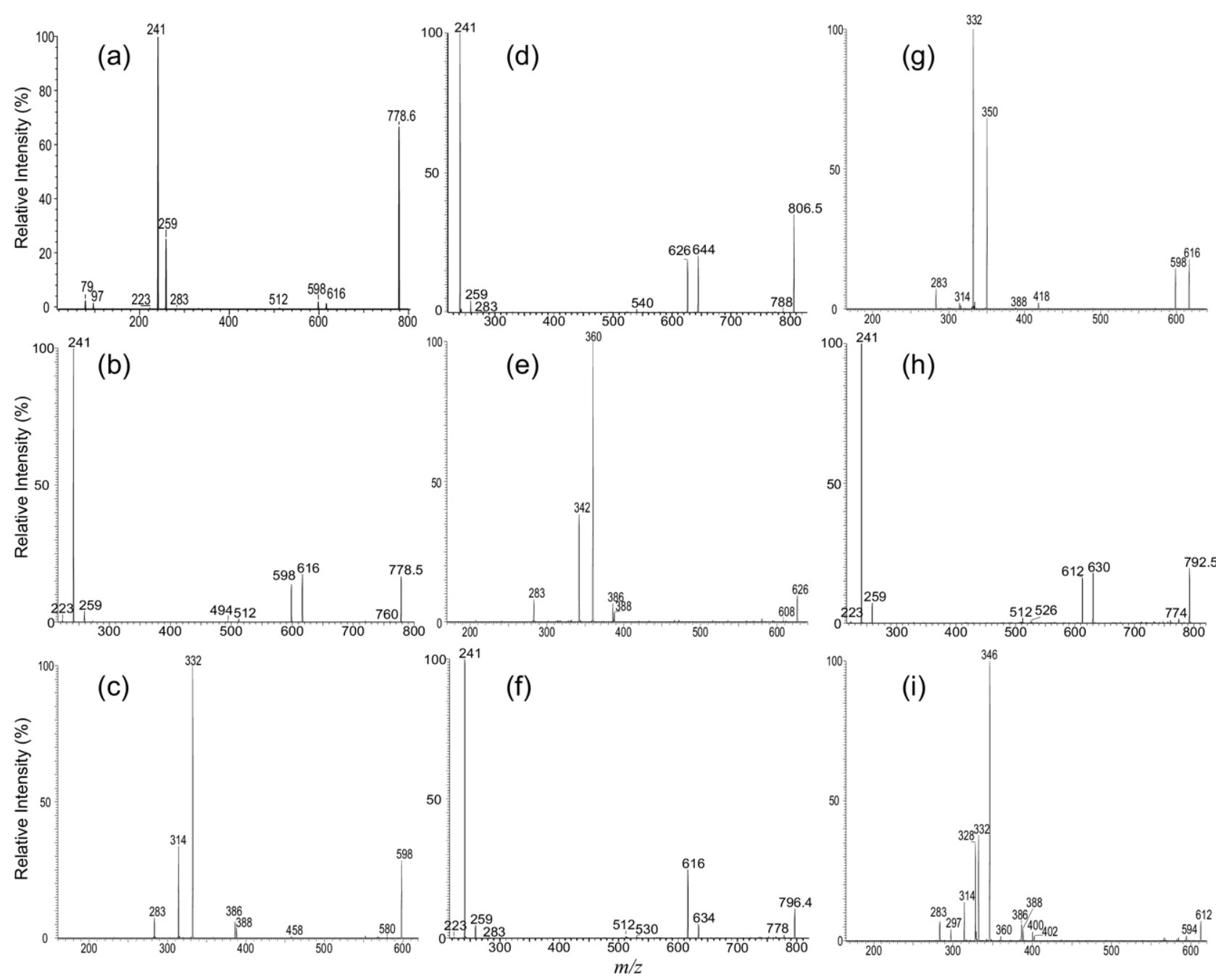

Figure 2. The $\mathrm{MS}^{2}$ product-ion spectra of the [M - H] $]^{-}$ion of d16:1/18:0-IPC at $m / z 778$ obtained with an ITMS (a), and a TSQ (b) instruments are similar and contain limited structural information. However, the IT MS ${ }^{3}$ spectrum of the ion at $m / z 598(778 \rightarrow 598)($ c) contains ions readily applicable for structural assignment. Similar results were also observed for the IT MS ${ }^{2}$ spectrum of the $[\mathrm{M}-\mathrm{H}]^{-}$ ion of d18:1/18:0-IPC at $m / z 806$ (d) and its IT MS ${ }^{3}$ spectrum of the ion at $m / z 626(806 \rightarrow 626)$ (e), for the IT MS ${ }^{2}$ spectrum of the $[\mathrm{M}-\mathrm{H}]^{-}$ion of $\mathrm{t} 16: 0 / 18: 0-\mathrm{IPC} \mathrm{m} / \mathrm{z} 796$ (f) and its $\mathrm{MS}^{3}$ spectrum of the ion at $m / z 616(796 \rightarrow 616)(\mathrm{g})$, and for the IT MS ${ }^{2}$ spectrum of the ion at $\mathrm{m} / \mathrm{z} 792(\mathbf{h})$ and its IT MS spectrum of the ion at $\mathrm{m} / \mathrm{z} 612(792 \rightarrow 612)(\mathbf{i})$, from which two isomeric structures were found.

the ions at $\mathrm{m} / \mathrm{z} 350(616-266)$ arising from loss of a 18:0-fatty acyl ketene and at $m / z 332\left(350-\mathrm{H}_{2} \mathrm{O}\right)$ arising from further loss of $\mathrm{H}_{2} \mathrm{O}$. The observation of these ions along with the ion at $\mathrm{m} / \mathrm{z} 283$ reflecting a 18:0-fatty acyl residue, clearly demonstrated that the molecule is, indeed, a t16:0/18:0-IPC. The distinction in the production spectra between, for example, d16:1/18:0-IPC and t16:0/18:0-IPC that are differed by their LCB moieties are also seen in the $\mathrm{MS}^{2}$ and $\mathrm{MS}^{3}$ spectra of the $[\mathrm{M}-2 \mathrm{H}$ $+\mathrm{Li}^{-},\left[\mathrm{M}+\mathrm{Li}^{+},[\mathrm{M}-\mathrm{H}+2 \mathrm{Li}]^{+}\right.$, and $[\mathrm{M}+\mathrm{H}]^{+}$ions (discuss later).

Several isobaric structures were observed for the ions at $m / z$ 750, 764, and 792 (Table 1). The IT MS spectrum of the ion at $\mathrm{m} / \mathrm{z} 792$ (Figure $2 \mathrm{~h}$ ), for example, contains the ions at $\mathrm{m} / \mathrm{z} 259,241,223,630(792-162)$, and $612(792-180)$ that are characteristic to an IPC. The spectrum also contains the ions at $\mathrm{m} / \mathrm{z} 526$ and 512 , corresponding to losses of 18:0- and 19:0-fatty acyl substituents, respectively. The structural assignment is further deduced from the IT MS ${ }^{3}$ spectrum of the ion at $m / z 612(792 \rightarrow 612)$ (Figure 2i), which contains two sets of the ion-pair at $\mathrm{m} / \mathrm{z} 346$ and 328, arising from loss of 18:0-fatty acyl substituent, and at $\mathrm{m} / \mathrm{z} 332$ and 314, arising from the analogous losses of the 19:0-fatty acyl substituent, along with the ions at $\mathrm{m} / \mathrm{z} 297$ and 283, corresponding to the 19:0- and 18:0-carboxylate anions, respectively. The spectrum also contains two sets of the ion-pair at $\mathrm{m} / \mathrm{z} 402$ and 400, arising from elimination of d16:1-LCB, and at $m / z 388$ and 386, arising from elimination of d17:1-LCB. The results demonstrated that the ion at $m / z 792$ is composed of both a d17:1/18:0-IPC and a d16:1/19:0-IPC structures. 
(a)

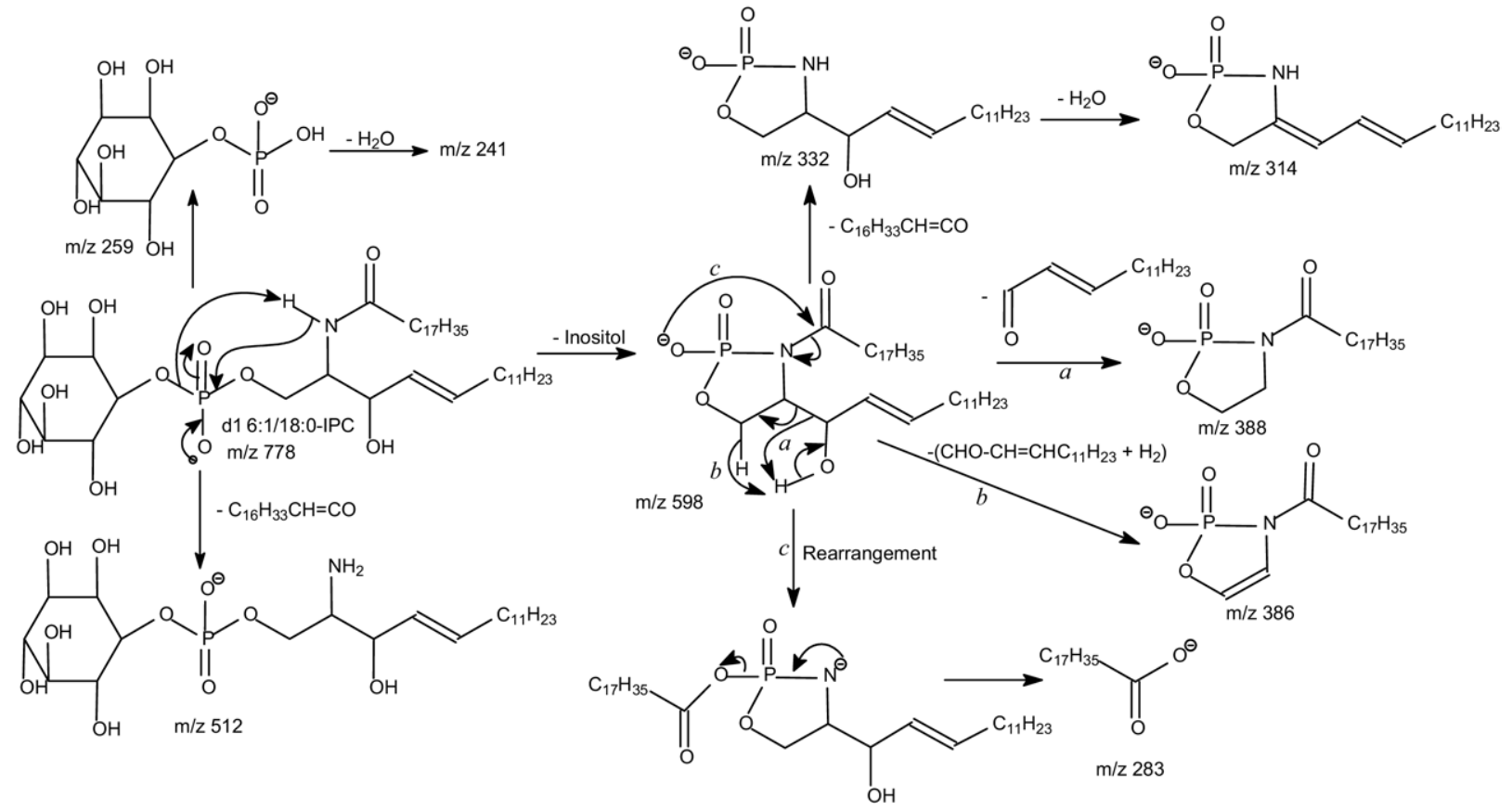

(b)
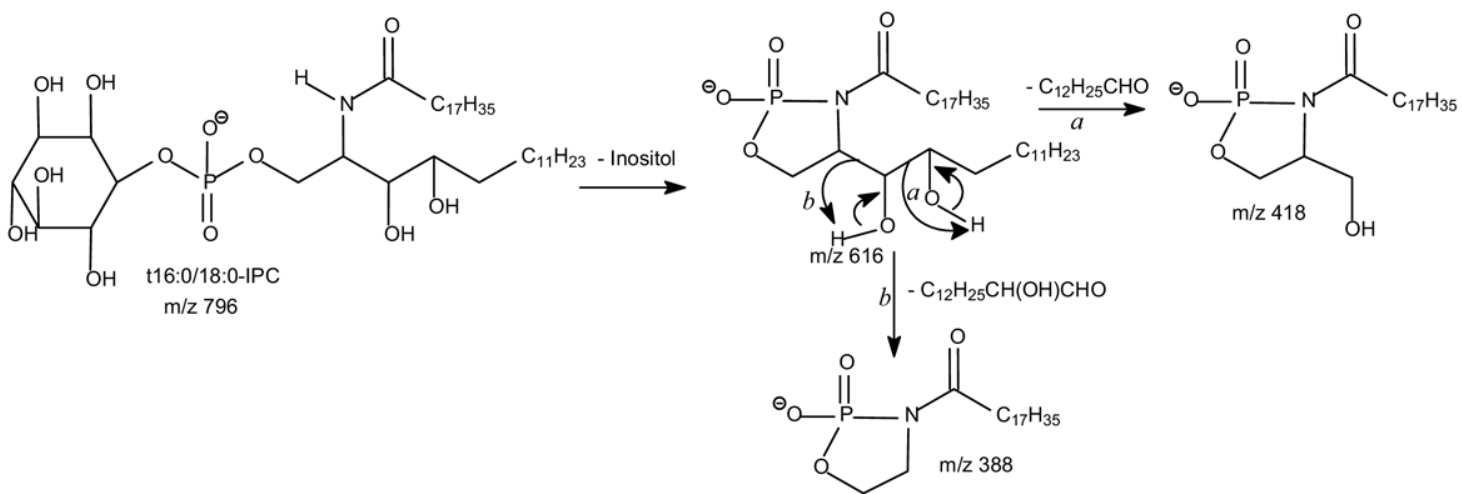

Scheme 1

Structural Characterization with the $[\mathrm{M}-2 \mathrm{H}+$ $\mathrm{Li}^{-}$Ions

Both the $\mathrm{MS}^{2}$ spectra of the $\left[\mathrm{M}-2 \mathrm{H}+\mathrm{Li}^{-}\right.$ion at $m / z 784$ (Table 1) obtained with IT (Figure 3a) and TSQ (not shown) instruments are dominated by the ion at $\mathrm{m} / \mathrm{z}$ 622 , corresponding to loss of a dehydrated inositol residue. The presence of the ions at $\mathrm{m} / \mathrm{z} 518(784-266)$ arising from loss of the 18:0-fatty acyl ketene and at $\mathrm{m} / \mathrm{z}$ $500\left(518-\mathrm{H}_{2} \mathrm{O}\right)$ from further loss of $\mathrm{H}_{2} \mathrm{O}$ indicate that the molecule contains a 18:0-fatty acyl substituent. Further dissociation of the ion at $\mathrm{m} / \mathrm{z} 622(784 \rightarrow 622)$ (Figure $3 \mathrm{~b}$ ), gives rise to ions at $m / z 604\left(622-\mathrm{H}_{2} \mathrm{O}\right)$ and 592 (622 - HCHO) via losses of $\mathrm{H}_{2} \mathrm{O}$ and $\mathrm{HCHO}$, respectively [31]. The fragmentation process leading to formation of the ion at $\mathrm{m} / \mathrm{z} 592$ may involve rearrangement of the phosphate residue to $\mathrm{C} 3$ from $\mathrm{C} 1$ position of the LCB, followed by loss of a HCHO residue (Scheme 2a, Route $a)$. The $\mathrm{MS}^{4}$ product-ion spectrum of the ion at $\mathrm{m} / \mathrm{z} 592(784 \rightarrow 622 \rightarrow 592)$ (Figure 3c) is dominated by the ion at $\mathrm{m} / \mathrm{z}$ 504, corresponding to loss of a $\mathrm{P}(\mathrm{OH})_{2}(\mathrm{OLi})$ (88 Da) residue (Scheme 2a), consistent with the proposed mechanism that involves rearrangement of the phosphate group. Similar rearrangement of phosphate group has been previously observed for phosphatidylinositol phosphate [30], phosphatidylserine [32], and plasmenylethanolamine [33].

In Figure $3 \mathrm{~b}$, the ion at $m / z 412$ probably arises from elimination of the LCB as an $\alpha, \beta$-unsaturated aldehyde as seen before (Scheme 2a, Route $b$ ); the ion at $m / z 356$ corresponds to loss of the 18:0-fatty acyl substituent. These results combined with the results from $\mathrm{MS}^{2}$ (Figure 3a) indicate that the compound is a d16:1/18:0IPC. Similarly, the IT MS ${ }^{2}$ spectrum of the $\left[\mathrm{M}-2 \mathrm{H}+\mathrm{Li}^{-}\right.$ ion at $\mathrm{m} / \mathrm{z} 812$ contains a major ion at $\mathrm{m} / \mathrm{z} 650$ (not shown) from loss of the inositol residue and the IT MS ${ }^{3}$ spectrum of $m / z$ 650 (812 $\rightarrow$ 650) (Figure 3d) also contains the analogous ions at $\mathrm{m} / \mathrm{z} 412$ and 384, arising from loss of a 18:1-LCB as an $\alpha, \beta$-unsaturated aldehyde 

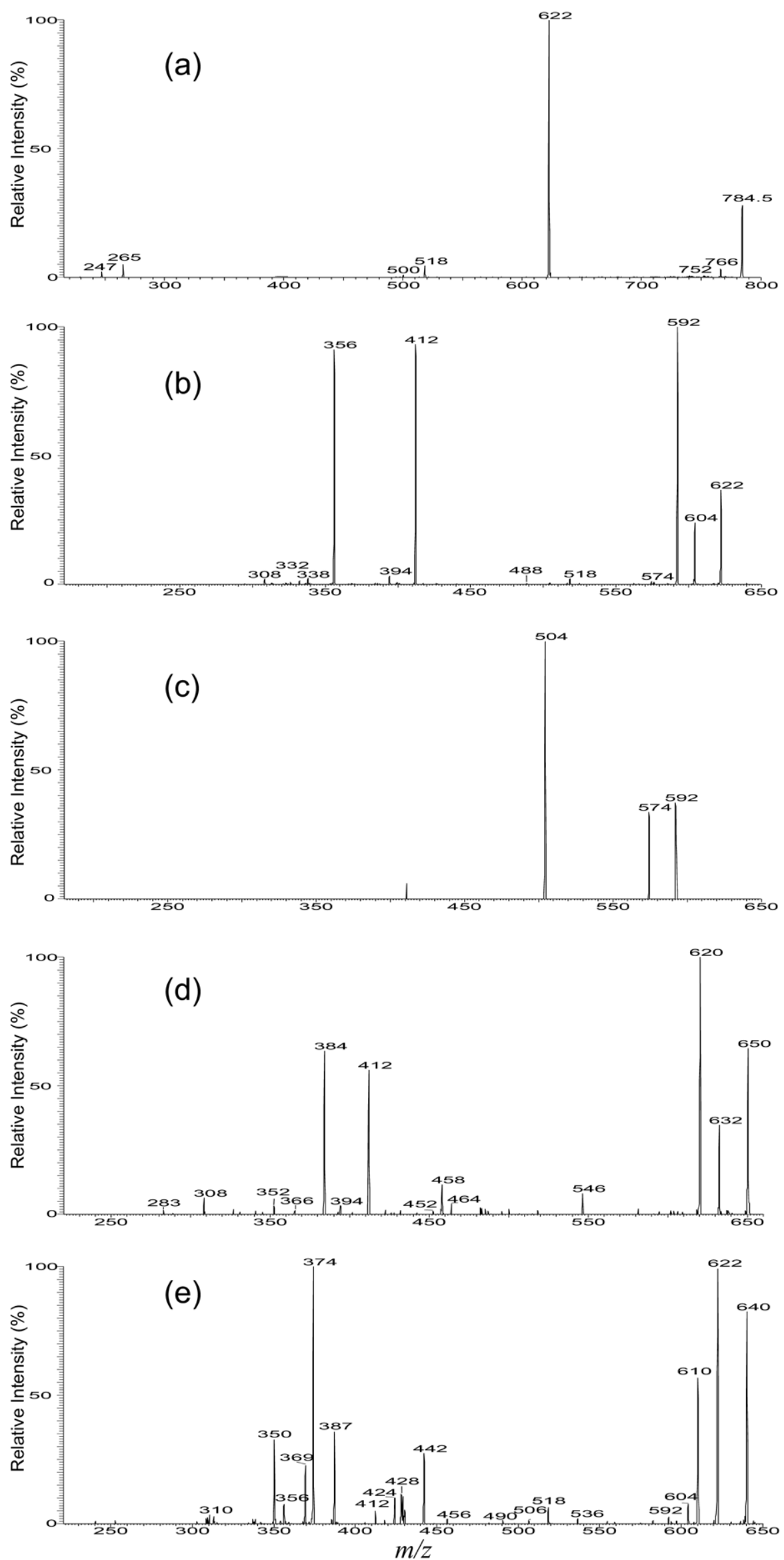

Figure 3. The IT MS ${ }^{2}$ spectra of the $\left[\mathrm{M}-2 \mathrm{H}+\mathrm{Li}^{-}\right.$ion at $m / z 784(\mathbf{a})$, its IT MS ${ }^{3}$ spectrum of the ion at $m / z 622(784 \rightarrow 622)(\mathbf{b})$, and its $\mathrm{MS}^{4}$ spectrum of the ion at $m / z 592(784 \rightarrow 622 \rightarrow 592)(\mathbf{c}) ;(\mathbf{d})$ is the IT MS ${ }^{3}$ spectrum of $\mathrm{m} / \mathrm{z} 650(812 \rightarrow 650)$ from d18:1/18:0-IPC; (e) is the IT MS ${ }^{3}$ spectrum of $\mathrm{m} / \mathrm{z} 640$ $(802 \rightarrow 640)$ from t16:0/18:0-IPC. 

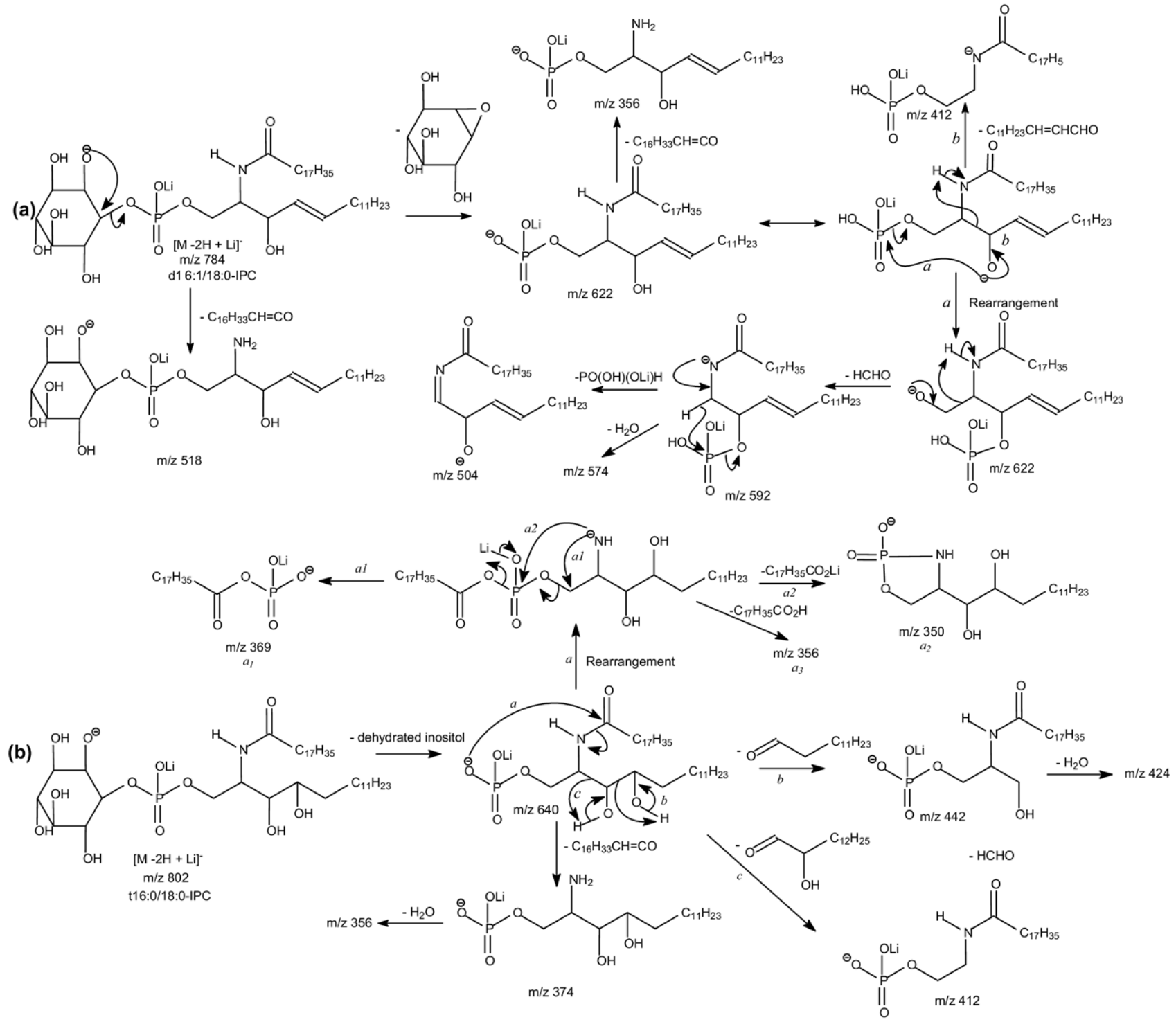

Scheme 2

and from loss of a 18:0-fatty acyl substituent, respectively. The observation of these ions, along with the ions at $m / z 632$ and 620, arising from further losses of $\mathrm{H}_{2} \mathrm{O}$ and $\mathrm{HCHO}$, respectively, suggests that the molecule is a d18:1/18:0-IPC, which is consistent with the structural assignment obtained from the $\left[\mathrm{M}-\mathrm{H}^{-}\right.$ion (Table 1).

The IT MS ${ }^{2}$ spectrum of the $\left[\mathrm{M}-2 \mathrm{H}+\mathrm{Li}^{-}\right.$ion at $\mathrm{m} / \mathrm{z}$ 802 (not shown) is, again, dominated by the ion at $\mathrm{m} / \mathrm{z}$ $640(802-162)$, which gives rise to the prominent ions at $m / z 622\left(640-\mathrm{H}_{2} \mathrm{O}\right)$ and $610(640-\mathrm{HCHO})$ as seen earlier (Figure 3e, $802 \rightarrow 640$ ). Nevertheless, the spectrum (Figure 3e) also contains the ion at $\mathrm{m} / \mathrm{z} 442$, probably arising from cleavage of the 3,4-dihydroxy bond of the t16:0-LCB to yield an alcohol by elimination of a tridecaldehyde (Scheme $\mathbf{2 b}$ ), and the ion at $\mathrm{m} / \mathrm{z} 412$, arising from loss of a 2-hydroxy-tetradecaldehyde, similar to the fragmentation processes as seen for the corresponding $[\mathrm{M}-\mathrm{H}]^{-}$ion of $\mathrm{m} / \mathrm{z} 796$ (Scheme $\mathbf{1 b}$ ). The 18:0-fatty acyl substituent is recognized by the observation of the prominent ion at $\mathrm{m} / \mathrm{z} 374(640-266)$, arising from loss of 18:0-fatty acyl ketene. The ion at $\mathrm{m} / \mathrm{z} 369$ may represent a stearoylphosphoric anion $\left(a_{1}\right.$ ion, Scheme $\mathbf{2 b}$ ), arising from a lipophosphoryl LCB via a prior rearrangement process (Scheme $\mathbf{2} \mathbf{b}$, Route $a$ ). This fragmentation process is consistent with the observation of the ions at $\mathrm{m} / \mathrm{z} 350\left(a_{2}\right)$ and $356\left(a_{3}\right)$, arising from further losses of the 18:0-fatty acid substituent as a lithium salt and as a free acid, respectively. These combined information lead to the assignment of a t16:0/18:0-IPC structure. By contrast, the $\mathrm{MS}^{3}$ spectrum from the sphingosine-containing IPC as shown in Figure $3 b$ is simple. The striking differences among the $\mathrm{MS}^{3}$ spectra arising from the IPCs with various LCBs are consistent with the distinction among the production spectra arising from their $[\mathrm{M}-\mathrm{H}]^{-}$ions as seen earlier. 

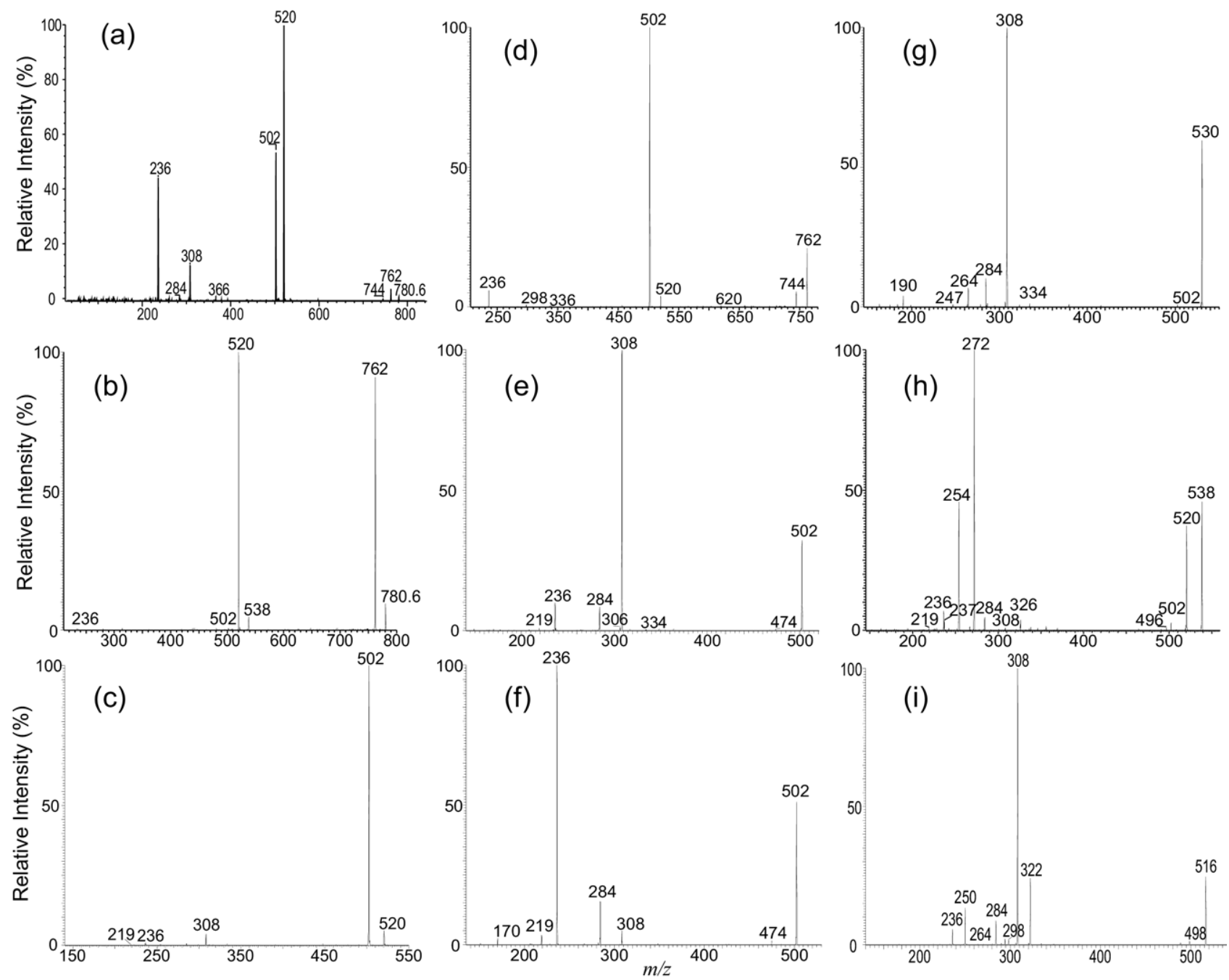

Figure 4. The $\mathrm{MS}^{2}$ product-ion spectra of the $[\mathrm{M}+\mathrm{H}]^{+}$ion at $m / z 780$ obtained with (a) a TSQ and (b) an IT instruments. The IT MS ${ }^{3}$ spectra of the ion at $\mathrm{m} / z 520(780 \rightarrow 520)(\mathbf{c})$, and of the ion at $\mathrm{m} / \mathrm{z}$ $762(780 \rightarrow 762)$ (d) provide limited structural information but the IT MS ${ }^{4}$ spectrum of $\mathrm{m} / \mathrm{z} 502$ originated from $m / z 520(780 \rightarrow 520 \rightarrow 502)(\mathbf{e})$ and from $m / z 762(780 \rightarrow 762 \rightarrow 502)(\mathbf{f})$ give abundant ions readily applicable for structure identification; $(\mathrm{g})$ is the IT MS ${ }^{4}$ spectrum of the ion at $\mathrm{m} / \mathrm{z} 530$ (808 $\rightarrow 548 \rightarrow 530)$ from the $[\mathrm{M}+\mathrm{H}]^{+}$ion of d18:1/18:0-IPC; $(\mathbf{h})$ is the IT MS ${ }^{3}$ spectrum of the ion at $m / z$ $538(798 \rightarrow 538)$ from the $[\mathrm{M}+\mathrm{H}]^{+}$ion of $\mathrm{t} 16: 0 / 18: 0-\mathrm{IPC} ;(\mathbf{i})$ is the IT MS ${ }^{4}$ spectrum of the ion at $m / z$ $516(794 \rightarrow 534 \rightarrow 516)$ arising from both a d17:1/18:0-IPC and a d16:1/19:0-IPC isomers.

Structural Characterization with the $[\mathrm{M}+\mathrm{H}]^{+}$, $[M+A l k]^{+}$, and $[M-H+2 A l k]^{-}$Ions

Among the most useful features in the product-ion spectra arising from the protonated and the alkali adduct ions of ceramide and sphingomyelin is that multiple sets of the fragment ions reflecting the identities of LCB and of fatty acyl substituent are present, leading to unequivocal structural determination [2729]. The structurally informative ions as described below are similar to those observed for the $[\mathrm{M}+\mathrm{H}]^{+}$and alkali adduct ions of ceramide and of sphingomyelin.

The $[\mathrm{M}+\mathrm{H}]^{+}$

The $\mathrm{MS}^{2}$ product-ion spectra of the $[\mathrm{M}+\mathrm{H}]^{+}$ion at $\mathrm{m} / \mathrm{z}$ 780 obtained with a TSQ (Figure 4a) and an IT (Figure 4b) instruments are dominated by the ion at $\mathrm{m} / \mathrm{z} 520$, arising from loss of the inositol monophosphate residue. The $\mathrm{m} / \mathrm{z} 520$ ion is equivalent to a protonated [Ceramide $-\mathrm{H}_{2} \mathrm{O}$ ] ion, which gives rise to the ion at $\mathrm{m} / \mathrm{z}$ 502 by elimination of $\mathrm{H}_{2} \mathrm{O}$. This is evidenced by observation of a prominent ion at $\mathrm{m} / \mathrm{z} 502$ in the IT $\mathrm{MS}^{3}$ spectrum of the ion at $\mathrm{m} / \mathrm{z} 520$ (Figure $4 \mathrm{c}, 780 \rightarrow 520$ ). The $m / z 502$ ion can also arise from $m / z 762$ by elimination of the inositol monophosphate residue. This fragmentation process is supported by the IT $\mathrm{MS}^{3}$ spectrum of $m / z 762(780 \rightarrow 762)$ (Figure $4 \mathrm{~d}$ ), in which the ion at $\mathrm{m} / \mathrm{z} 502$ is prominent. Both the IT MS ${ }^{4}$ spectra of the ion at $\mathrm{m} / \mathrm{z} 502$ originated from $\mathrm{m} / \mathrm{z} 520(780 \rightarrow 520 \rightarrow 502$, Figure $4 \mathrm{e})$ and from $m / z 762(780 \rightarrow 762 \rightarrow 502$, Figure 4f) contain ions at $\mathrm{m} / \mathrm{z} 308$ and 284, identifying the 18:0-fatty acyl substituent, along with the ions at $\mathrm{m} / \mathrm{z}$ 


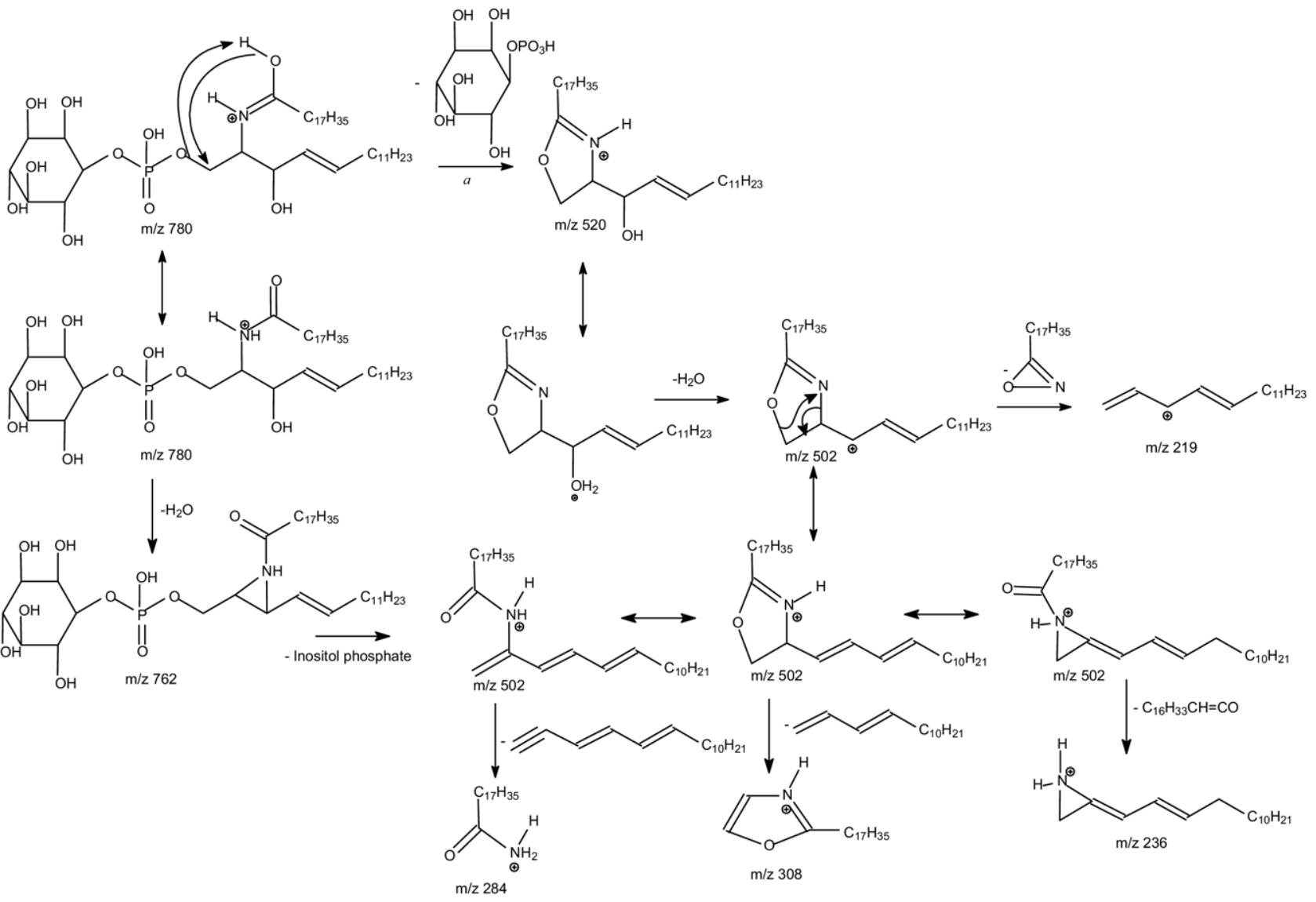

Scheme 3

236 and 219 reflecting the d16:1-LCB moiety [23, 27, 28]. However, the ion at $m / z 308$ is the most prominent in Figure 4e; whereas the ion at $\mathrm{m} / \mathrm{z} 236$ is the most prominent in Figure $4 \mathrm{f}$. The apparent differences between the two IT MS ${ }^{3}$ spectra from the $m / z 502$ ions may be attributable to the fact that the mechanism leading to dissociation of $m / z 502$ as seen in Figure 4e involved in a prior formation of 5-member cyclic ring intermediate as previously proposed (Scheme 3a) [29], while the mechanism leading to dissociation of $m / z 502$ as seen in Figure $4 \mathrm{f}$ involved a prior formation of an aziridine intermediate (Scheme $3 b$ ). Similar results were also observed for the $[\mathrm{M}+\mathrm{H}]^{+}$ion at $m / z$ 806, which undergoes consecutive losses of inositol monophosphate and $\mathrm{H}_{2} \mathrm{O}$ to yield ions at $m / z 548$ and 530, respectively (data not shown). The IT $\mathrm{MS}^{4}$ spectrum of the ion at $m / z 530(808 \rightarrow 548 \rightarrow 530)$ (Figure $4 \mathrm{~g}$ ) contains the ions at $m / z 308$ and 284, reflecting the 18:0-fatty acyl substituent, along with the ions at $\mathrm{m} / \mathrm{z}$ 264 and 247 that are 28 Da higher than the analogous ions observed for d16:1/18:0-IPC (i.e., the $\mathrm{m} / \mathrm{z} 236$ and 219 ions) and are signifying the presence of d18:1-LCB residue.

Both the IT and TSQ MS ${ }^{2}$ product-ion spectra of the $[\mathrm{M}+\mathrm{H}]^{+}$ion at $m / z 798$ are dominated by the ion at $m / z$ 538 (not shown), arising from loss of inositol monophosphate. The IT $\mathrm{MS}^{3}$ spectrum of the ion at $\mathrm{m} / \mathrm{z} 538$
(798 $\rightarrow$ 538, Figure $4 \mathrm{~h}$ ) contains the ions at $m / z 520$ and 272 from further losses of $\mathrm{H}_{2} \mathrm{O}$ and 18:0-fatty acyl ketene, respectively. However, the ions at $\mathrm{m} / \mathrm{z} 308$ and 284, reflecting the 18:0-fatty acyl residue, along with the ions at $m / z 254$ and 237, reflecting the t16:0-LCB, residue were also seen. Similar ions (i.e., the $m / z$ 308, 282, 254, and 237 ions) were also observed in the $\mathrm{MS}^{4}$-spectrum of the ion at $m / z 520(798 \rightarrow 538 \rightarrow 520)$ (data not shown). The results are consistent with the assignment of the t16:0/18:0-IPC structure deduced from the [M $\mathrm{H}]^{-}$ion at $m / z 796$ as described earlier. The $\mathrm{MS}^{3}$ spectrum is readily distinguishable from that arising from the IPC consisting of sphingosine, such as d16:1/18:0IPC (Figure 4c), which would require $\mathrm{MS}^{4}$ spectrum for its structural identification.

The tandem mass spectrometric approach that reveals the multiple isobaric structures of IPCs in the [M $+\mathrm{H}]^{+}$form is exemplified by the ion at $m / z 794$, which gives rise to a prominent ion at $m / z 534$ (794-260) (not shown), which further dissociated to $\mathrm{m} / \mathrm{z} 516$ (534 $\mathrm{H}_{2} \mathrm{O}$ ) by a water loss (not shown). The $\mathrm{MS}^{4}$ spectrum of the ion at $m / z 516(794 \rightarrow 534 \rightarrow 516)$ (Figure 4 i) contains two sets of the ion-pair at $\mathrm{m} / \mathrm{z} 322 / 298$ and 308/284, indicating the presence of 19:0- and 18:0-fatty acyl substituents, respectively. The spectrum (Figure $4 \mathrm{~g}$ ) also contains two sets of the ion-pair at $m / z 250 / 233$ and $236 / 219$ that signify the presence of $17: 1-\mathrm{LCB}$ and 

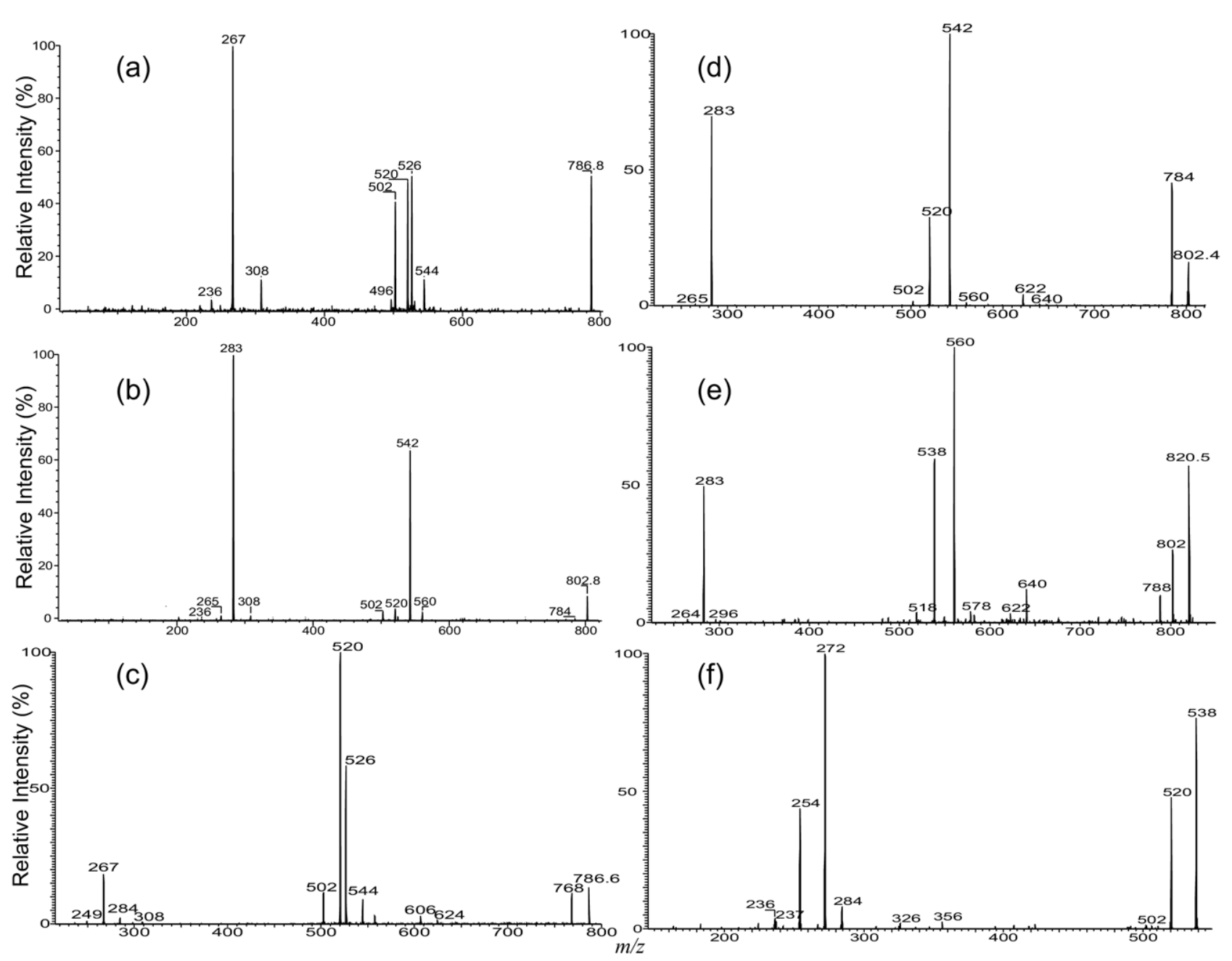

(f)

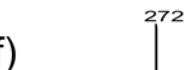

Figure 5. The $\mathrm{MS}^{2}$ product-ion spectra of (a) the $[\mathrm{M}+\mathrm{Li}]^{+}$ion at $m / z 786,(\mathbf{b})$ of the $[\mathrm{M}+\mathrm{Na}]^{+}$ion at $m / z 802(\mathbf{b})$ obtained with a TSQ, and of the $[\mathrm{M}+\mathrm{Li}]^{+}$ion at $m / z 786(\mathbf{c})$, and of the $[\mathrm{M}+\mathrm{Na}]^{+}$ion at $\mathrm{m} / \mathrm{z} 802$ (d) obtained with an IT instrument. The IT $\mathrm{MS}^{2}$ spectrum of the $\left[\mathrm{M}+\mathrm{Na}^{+}\right.$ion of t16:0/18:0-IPC at $m / z 820\left(\right.$ e) and its IT MS ${ }^{3}$-spectrum of the ion at $m / z 538(820 \rightarrow 538)(\mathbf{f})$ are also shown.

16:1-LCB, respectively. The major set of the $m / z 308 / 284$ ion-pair is formed concurrently with the $\mathrm{m} / \mathrm{z} 250 / 237$ ion-pair, arising from the major d17:1/18:0-IPC structure; while the minor $\mathrm{m} / \mathrm{z} 322 / 298$ ion-pair is formed together with the set of $\mathrm{m} / \mathrm{z} 236 / 219$ ion-pair, arising from a minor d16:1/19:0-IPC species. Again, the structural assignment is consistent with that deduced from the $[\mathrm{M}-\mathrm{H}]^{-}$ion at $\mathrm{m} / \mathrm{z} 792$ (Figure 2i) (Table 1).

\section{The $[M+A l k]^{+}(A l k=L i, N a)$ Ions}

The major fragmentation process observed for the $[\mathrm{M}+$ $\mathrm{Alk}^{+}(\mathrm{Alk}=\mathrm{Li}, \mathrm{Na})$ ion of IPC also arises from cleavage of the inositol monophosphate residue. This is seen in the tandem quadrupole product-ion spectrum of the $[\mathrm{M}+\mathrm{Li}]^{+}$ion at $\mathrm{m} / \mathrm{z} 786$ (Figure 5a), which contains prominent ions at $\mathrm{m} / \mathrm{z} 526(786-260)$ arising from elimination of inositol monophosphate residue and at $m / z 267\left(\left[\mathrm{C}_{6} \mathrm{H}_{11} \mathrm{O}_{5} \mathrm{OPO}(\mathrm{OH})_{2}+\mathrm{Li}^{+}\right)\right.$, corresponding to a lithiated adduct ion of inositol mono- phosphate. The ion at $\mathrm{m} / \mathrm{z} 544$ (Figure 5a) is equivalent to a lithiated ceramide ion and gives rise to ions at $\mathrm{m} / \mathrm{z}$ $526,520,502$, and 496 , as well as the ions at $\mathrm{m} / \mathrm{z} 308$ and 236, reflecting the 18:0-fatty acyl and 16:1-LCB moieties, respectively [27-29]. Similar results were also observed for the $[\mathrm{M}+\mathrm{Na}]^{+}$ion at $m / z 802$ (Figure $5 b$ ), which is dominated by the analogous ions at $\mathrm{m} / z 542(802-260)$ and $m / z 283\left(\left[\mathrm{C}_{6} \mathrm{H}_{11} \mathrm{O}_{5} \mathrm{OPO}(\mathrm{OH})_{2}+\mathrm{Na}\right]^{+}\right)$, along with ions at $\mathrm{m} / \mathrm{z} 308$ and 236 that reflect the 18:0-fatty acyl and 16:1-LCB, respectively. The IT MS ${ }^{2}$ spectra of the ions at $\mathrm{m} / \mathrm{z} 786$ (Figure $5 \mathrm{c}$ ) and at $\mathrm{m} / \mathrm{z} 802$ (Figure $5 \mathrm{~d}$ ) are similar to those obtained with TSQ, but the ions reflecting the fatty acyl and LCB moieties are not present. However, the IT MS ${ }^{4}$ spectra of the ions at $m / z 502$ (786 $\rightarrow 520 \rightarrow 502$ ) (not shown) are identical to that shown in Figure 4e, which gives assignment of the 18:0-fatty acyl and 16:1-LCB moieties.

The IT MS 2 spectrum of the $[\mathrm{M}+\mathrm{Na}]^{+}$ion at $m / z 820$ (Figure 5e) is also dominated by the ions at $\mathrm{m} / \mathrm{z} 560(820$ - 260) and $538(820-282)$, arising from losses of the 

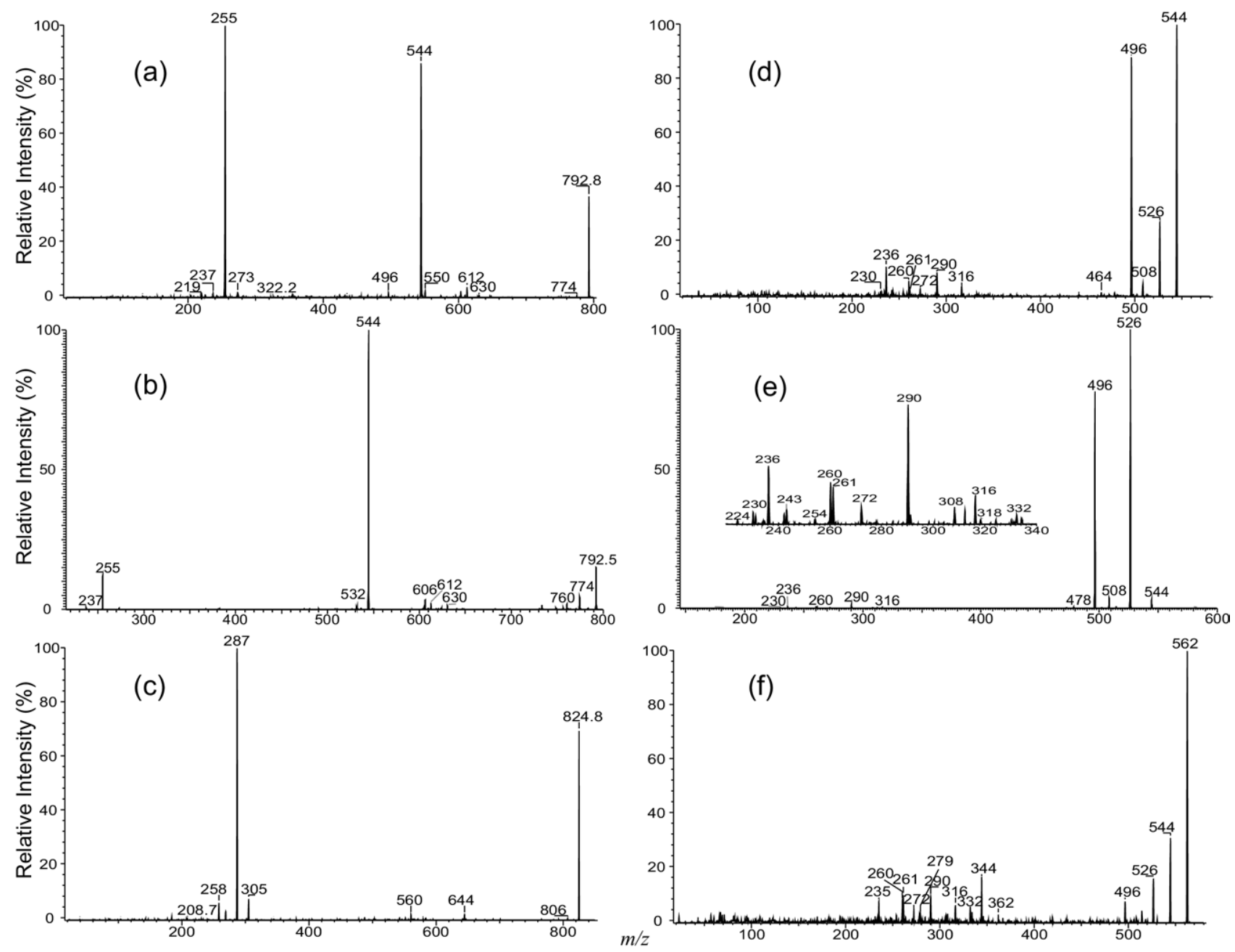

Figure 6. The $\mathrm{MS}^{2}$ product-ion spectra of the $[\mathrm{M}-\mathrm{H}+2 \mathrm{Li}]^{+}$ion of $\mathrm{d} 16: 1 / 18: 0-\mathrm{IPC}$ at $\mathrm{m} / \mathrm{z} 792$ obtained with (a) a TSQ, (b) an IT instruments, and the tandem quadrupole product-ion spectrum of the corresponding $[\mathrm{M}-\mathrm{H}+2 \mathrm{Na}]^{+}$ion at $\mathrm{m} / z 824$ (c). The product-ion spectrum of the ion at $\mathrm{m} / \mathrm{z} 544$ from source CAD $(\mathbf{d})$, and from $\mathrm{MS}^{3}(792 \rightarrow 544)$ with IT $(\mathbf{e})$ are also shown; (f) is the product-ion spectrum of the ion at $\mathrm{m} / \mathrm{z} 562$, generated by skimmer CAD on the $[\mathrm{M}-\mathrm{H}+2 \mathrm{Li}]^{+}$ion of $\mathrm{t} 16: 0 / 18: 0-\mathrm{IPC}$ at $\mathrm{m} / \mathrm{z} 810$.

inositol monophosphate as an acid and as a sodium salt, respectively, along with the ion at $\mathrm{m} / \mathrm{z} 283$ $\left(\left[\mathrm{C}_{6} \mathrm{H}_{11} \mathrm{O}_{5} \mathrm{OPO}(\mathrm{OH})_{2}+\mathrm{Na}\right]^{+}\right)$. The ions informative to the identities of the 18:0-fatty acyl and t16:0-LCB residues are not present in the spectrum, but the IT $\mathrm{MS}^{3}$-spectrum of the ion at $m / z 538(820 \rightarrow 538)$ (Figure $5 \mathrm{f}$ ) is identical to that shown in Figure $4 \mathrm{~h}$, which represents the t16:0/18:0-IPC structure. Similar results were also observed for the $[\mathrm{M}+\mathrm{Li}]^{+}$ion at $m / z 804$ (data not shown).

\section{The $[M-H+2 A l k]^{-}(A l k=L i, N a)$ Ions}

The major ions observed for the $[\mathrm{M}-\mathrm{H}+2 \mathrm{Alk}]^{+}$ion of IPC arises from cleavage of the $\mathrm{P}-\mathrm{OC}_{1}$ bond, similar to that previously observed for the $[\mathrm{M}-\mathrm{H}+2 \mathrm{Alk}]^{+}$of phosphatidylserine [32]. As seen in Figure 6, the MS product-ion spectra of the $[\mathrm{M}-\mathrm{H}+2 \mathrm{Li}]^{+}$ion at $m / z 792$ obtained with an TSQ (Figure 6a) and with an IT
(Figure 6b) instruments are dominated by the ions at $\mathrm{m} / \mathrm{z} 544$ and 255 , corresponding to a lithiated ceramide and a dilithiated inositol-1,2-cyclic phosphate ions, respectively (Scheme 4). In contrast, the product-ion spectrum of the corresponding $[\mathrm{M}-\mathrm{H}+2 \mathrm{Na}]^{+}$ion at $\mathrm{m} / \mathrm{z}$ 824 (Figure 6c) is dominated by a disodiated inositol1,2-cyclic phosphate ion at $\mathrm{m} / \mathrm{z} 287$, and the ion at $\mathrm{m} / \mathrm{z}$ 560 , corresponding to a sodiated ceramide cation, is of low abundance. This drastic rise in the abundance of the alkali phosphate cations upon substitution of $\mathrm{Li}^{+}$with $\mathrm{Na}^{+}$was previously seen for the $[\mathrm{M}-\mathrm{H}+2 \mathrm{Alk}]^{+}$of phosphatidylserine [32].

The fragment ions informative for the fatty acyl substituent and LCB are not present in the $\mathrm{MS}^{2}$ spectra (Figure 6a-c). However, the product-ion spectrum of the ion at $m / z 544$ (Figure 6d) generated by source CAD and the IT MS ${ }^{3}$ spectrum of the ion at $m / z 544(792 \rightarrow$ 544) (Figure 6e) contains the ions at $m / z 236,260$, and 261 , signifying the 16:1-LCB moiety, along with the ions 


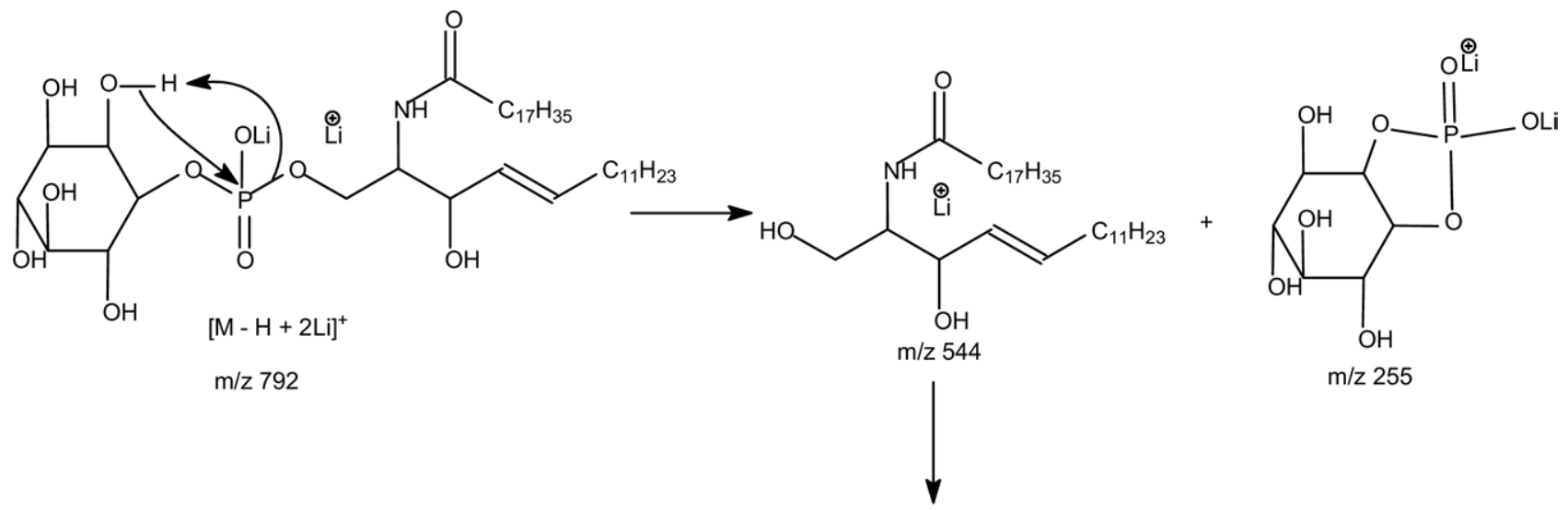

Undergo further fragmentation similar to monolithiated ceramide

Scheme 4

at $m / z 272,290$, and 316, identifying the 18:0-fatty acyl substituent. These ions are similar to those observed for the $[\mathrm{M}+\mathrm{Li}]^{+}$ion of ceramide with a sphingosine moiety [27-29], supporting the assignment of the d16: 1/18:0-IPC structure. These results are consistent with the notion that the ions informative for structural identification of the $[\mathrm{M}+\mathrm{Li}]^{+}$ion of the d16:1/18:0-IPC arise from further fragmentation of $m / z 544$, a lithiated d16:1/18:0-ceramide. Similarly, the product-ion spectrum of the ion at $m / z 562$ (Figure 6f), generated by source CAD on the $[\mathrm{M}-\mathrm{H}+2 \mathrm{Li}]^{+}$ion of $\mathrm{t} 16: 0 / 18: 0-\mathrm{IPC}$ at $m / z 810$, contains analogous ions arising from the [M $+\mathrm{Li}^{+}$ion of $\mathrm{t} 16: 0 / 18: 0$-ceramide at $m / z$ 562. These ions (Figure 6f) were seen at $m / z 279,261,260$, and 235 that identify the t16:0-LCB, as well as the ions at $m / z 344$, $332,316,290$, and 272 that identify the 18:0-fatty acyl moiety [28].

\section{Profiling the IPC Species by Linked-Scanning}

As shown earlier, the ions at $m / z 259$ and 241 are common ions observed in the $\mathrm{MS}^{2}$ spectra of the [M $\mathrm{H}^{-}$ions of IPCs and are among the most prominent (Figure 2). The $\mathrm{MS}^{2}$ spectra obtained by parent-ion scans of 241 (Figure 1b) and of 259 (Figure 1c) are similar to the MS spectrum shown in Figure 1a, suggesting that the $\mathrm{MS}^{2}$ spectra arising from these scans may be applicable for profiling the IPCs in mixtures, similar to that previously described for phosphatidylinositol [30]. The profiles of the $\mathrm{MS}^{2}$ spectra acquired by neutral losses of 260 (loss of $\mathrm{C}_{6} \mathrm{H}_{11} \mathrm{O}_{6} \mathrm{PO}[\mathrm{OH}]_{2}$ ) (Figure 1d), of 266 (loss of $\mathrm{C}_{6} \mathrm{H}_{11} \mathrm{O}_{6} \mathrm{PO}[\mathrm{OH}][\mathrm{OLi}]$ ) (Figure 1e), and of 248 (loss of $\mathrm{C}_{6} \mathrm{H}_{10} \mathrm{O}_{6} \mathrm{PO}[\mathrm{H}][\mathrm{OLi}]$ ) (Figure 1f), from the IPCs observed in the forms of $[\mathrm{M}+\mathrm{H}]^{+},[\mathrm{M}+$ $\mathrm{Li}]^{+}$, and $[\mathrm{M}-\mathrm{H}+\mathrm{Li}]^{+}$, respectively, are also similar, indicating the $\mathrm{MS}^{2}$ spectra from these neutral loss (NL) scans may be also useful for detecting IPC molecules. However, the sensitivities of IPCs detected by ESI as the $[\mathrm{M}+\mathrm{H}]^{+},[\mathrm{M}+\mathrm{Li}]^{+}$, and $[\mathrm{M}-\mathrm{H}+\mathrm{Li}]^{+}$forms are at least 10 times less than the $[\mathrm{M}-\mathrm{H}]^{-}$form, resulting in decrease in sensitivities using the corresponding NL scannings (i.e., NL scannings of 260, 266, and 248), regardless of the fact that the $[\mathrm{M}+\mathrm{H}-260]^{+}(\mathrm{NL}$ of $260),[\mathrm{M}+\mathrm{Li}-266]^{+}(\mathrm{NL}$ of 266), and $[\mathrm{M}-\mathrm{H}+2 \mathrm{Li}-$ $248]^{+}$(NL of 248) ions are among the most prominent in the product-ion spectra of IPC seen as the $[\mathrm{M}+\mathrm{H}]^{+}$ (e.g., Figure $4 a),[\mathrm{M}+\mathrm{Li}]^{+}$(e.g., Figure $\left.5 \mathrm{a}\right)$ and as the $[\mathrm{M}-\mathrm{H}+2 \mathrm{Li}]^{+}$(e.g., Figure 6a) ions, respectively.

\section{Conclusions}

Multiple-stage IT mass spectrometry with subsequent applications of $\mathrm{MS}^{3}$ and $\mathrm{MS}^{4}$ and tandem quadrupole mass spectrometry with application of source CAD afford the fragmentation processes of IPC under lowenergy CAD to be unveiled in detail, leading to its structural characterization. While multiple-stage mass spectrometry, in particular with IT, provides information that is valuable to the understanding of the mechanism(s) underlying the fragmentation processes, tandem quadrupole mass spectrometry with application of precursor-ion or NL scanning is useful for specific detection of IPC species in mixture from biological specimens. The observation of the d16:1/18:0-IPC as the most abundant IPC from this study (Table 1) suggests that the majority of LCB in Leishmania major is synthesized through the condensation of serine and myristoylCoA (14:0). This unique requirement for myristoyl-CoA in the IPC synthesis in Leishmania major is similar to the synthesis of lipid anchor for the variant surface glycoprotein in a related protozoan parasite, Trypanosoma brucei [34].

\section{Acknowledgments}

Research at the Mass Spectrometry Resource of Washington University was supported by U.S. Public Health Service grants P41-RR-00954, R37-DK-34388, P60-DK-20579, P01-HL-57278, P30DK56341, and AI31078 (SMB). 


\section{References}

1. Smith, S. W; Lester, R. L. Inositol Phosphorylceramide, a Novel Substance and the Chief Member of a Major Group of Yeast Sphingolipids Containing a Single Inositol Phosphate. J. Biol. Chem. 1974, 249, 33953405 .

2. Wagner, H.; Zofcsik, W. On New Sphingolipids of Yeast. Biochem. Zeitschrift 1966, 344, 314-316.

3. Carter, H. E.; Celmer, W. D.; Lands, W. E.; Mueller, K. L.; Tomizawa, H. H. Biochemistry of the Sphingolipids. VIII. Occurrence of a Long Chain Base in Plant Phosphatides. J. Biol. Chem. 1954, 206, 613-623.

4. Hetherington, A. M.; Drobak, B. K. Inositol-Containing Lipids in Higher Plants. Prog Lipid Res 1992, 31, 53-63.

5. Kaneshiro, E. S.; Jayasimhulu, K.; Lester, R. L. Characterization of Inositol Lipids from Leishmania donovani Promastigotes: Identification of an Inositol Sphingophospholipid. J. Lipid Res. 1986, 27, 1294-1303.

6. Guther, M. L.; Lee, S.; Tetley, L.; Acosta-Serrano, A.; Ferguson, M. A. GPI-Anchored Proteins and Free GPI Glycolipids of Procyclic Form Trypanosoma brucei are Nonessential for Growth, are Required for Colonization of the Tsetse Fly, and are not the Only Components of the Surface Coat. Mol. Biol. Cell 2006, 17, 5265-5274

7. Serrano, A. A.; Schenkman, S.; Yoshida, N.; Mehlert, A.; Richardson, J. M.; Ferguson, M. A. The Lipid Structure of the Glycosylphosphatidylinositol-Anchored Mucin-Like Sialic Acid Acceptors of Trypanosoma cruzi Changes During Parasite Differentiation from Epimastigotes to Infective Metacyclic Trypomastigote Forms. J. Biol. Chem. 1995, 270, 27244-27253.

8. Denny, P. W.; Field, M. C.; Smith, D. F. GPI-Anchored Proteins and Glycoconjugates Segregate into Lipid Rafts in Kinetoplastida. FEBS Lett. 2001, 491, 148-153.

9. Lester, R. L; Dickson, R. C. Sphingolipids with InositolphosphateContaining Head Groups. Adv. Lipid Res. 1993, 26, 253-274.

10. Becker, G. W.; Lester, R. L. Biosynthesis of Phosphoinositol-Containing Sphingolipids from Phosphatidylinositol by a Membrane Preparation from Saccharomyces cerevisiae. J. Bacteriol. 1980, 142, 747-754.

11. Dickson, R. C.; Lester, R. L. Yeast sphingolipids. Biochim. Biophys. Acta $1999,1426,347-357$

12. Figueiredo, J. M.; Dias, W. B.; Mendonca-Previato, L.; Previato, J. O.; Heise, N. Characterization of the Inositol Phosphorylceramide Synthase Activity from Trypanosoma cruzi. Biochem. J. 2005, 387, 519-529.

13. Wells, G. B.; Dickson, R. C.; Lester, R. L. Isolation and Composition of Inositolphosphorylceramide-Type Sphingolipids of Hyphal Forms of Candida albicans. J. Bacteriol. 1996, 178, 6223-6226.

14. Nagiec, M. M.; Nagiec, E. E.; Baltisberger, J. A.; Wells, G. B.; Lester, R. L.; Dickson, R. C. Sphingolipid Synthesis as a Target for Antifungal Drugs. Complementation of the Inositol Phosphorylceramide Synthase Defect in a Mutant Strain of Saccharomyces cerevisiae by the AUR1 gene. J. Biol. Chem. 1997, 272, 9809-9817.

15. Mandala, S. M.; Thornton, R. A.; Rosenbach, M.; Milligan, J.; GarciaCalvo, M. Bull, H. G. Kurtz, M. B. Khafrefungin, a Novel Inhibitor of Sphingolipid Synthesis. J. Bio. Chem. 1997, 272, 32709-32714.

16. Zhong, W.; Jeffries, M. W.; Georgopapadakou. N. H. Inhibition of Inositol Phosphorylceramide Synthase by Aureobasidin A in Candida and Aspergillus Species. Antimicrob. Agents Chemother. 2000, 44, 651-653.

17. Mare, L.; Iatta, R.; Montagna, M. T.; Luberto, C.; Del Poeta, M. APP1 Transcription is Regulated by Inositol-Phosphorylceramide Synthase 1-Diacylglycerol Pathway and is Controlled by ATF2 Transcription Factor in Cryptococcus neoformans. J. Biol. Chem. 2005, 280, 36055-36064.

18. Heung, L. J.; Luberto, C.; Plowden, A.; Hannun, Y. A.; Del Poeta, M. The Sphingolipid Pathway Regulates Pkc1 Through the Formation of Diacylglycerol in Cryptococcus neoformans. J. Biol. Chem. 2004, 279, 21144ylglycero.
21153.
19. Zhang, K.; Showalter, M.; Revollo, J.; Hsu, F. F.; Turk, J.; Beverley, S. M. Sphingolipids are Essential for Differentiation but not Growth in Leishmania. EMBO J. 2003, 22, 6016-6026.

20. Zhang; K.; Hsu; F. F.; Scott; D. A.; Docampo; R.; Turk; J.; Beverley; S. M. Leishmania Salvage and Remodeling of Host Sphingolipids in Amastigote Survival and Acidocalcisome Biogenesis. Mol. Microbiol. 2005,55, $1566-1578$.

21. Denny, P. W.; Goulding, D.; Ferguson, M. A.; Smith, D. F. SphingolipidFree Leishmania are Defective in Membrane Trafficking, Differentiation, and Infectivity. Mol. Microbiol. 2004, A52, 313-327.

22. Zhang, K.; Pompey, J. M.; Hsu, F. F.; Key, P.; Bandhuvula, P.; Saba, J. D. Turk, J.; Beverley, S. M. Redirection of Sphingolipid Metabolism Toward de Novo Synthesis of Ethanolamine in Leishmania. EMBO J. 2007, 26, 1094-1104.

23. Singh, B. N.; Costello, C. E.; Beach, D. H.; Holz, G. G. Jr. Di-O Alkylglycerol, mono-O-Alkylglycerol and Ceramide Inositol Phosphates of Leishmania Mexicana Mexicana promastigotes. Biochem. Biophys. Res. Commun. 1988, 157, 1239-1246.

24. Levery, S. B.; Toledo, M. S.; Straus, A. H.; Takahashi, H. K. Comparative Analysis of Glycosylinositol Phosphorylceramides from Fungi by Electrospray Tandem Mass Spectrometry with Low-Energy Collision-Induced Dissociation of $\mathrm{Li}(+)$ Adduct Ions. Rapid Commun. Mass Spectrom. 2001, 15, 2240-2258.

25. Toledo, M. S.; Levery, S. B.; Glushka, J.; Straus, A. H.; Takahashi, H. K. Structure Elucidation of Sphingolipids from the Mycopathogen Sporothrix schenckii: Identification of Novel Glycosylinositol Phosphorylceramides with Core Manalpha1->6I ns Linkage. Biochem. Biophys. Res. Commun. 2001, 280, 19-24.

26. Bennion, B.; Park, C.; Fuller, M.; Lindsey, R.; Momany, M.; Jennemann, R.; Levery, S. B. Glycosphingolipids of the Model Fungus Aspergillus nidulans: Characterization of GIPCs with Oligo- $\alpha$-Mannose-Type Glycans. J. Lipid Res. 2003, 44, 2073-2088.

27. Hsu, F. F.; Turk, J. Structural Determination of Sphingomyelin by Tandem Mass Spectrometry with Electrospray Ionization. J. Am. Soc. Mass Spectrom. 2000, 11, 437-449.

28. Hsu, F. F.; Turk, J.; Stewart, M. E.; Downing, D. T. Structural Studies on Ceramides as Lithiated Adducts by Low Energy Collisional-Activated Dissociation Tandem Mass Spectrometry with Electrospray Ionization. J. Am. Soc. Mass Spectrom. 2002, 13, 680-695

29. Hsu, F. F.; Turk, J. Tandem Mass Spectrometry with Electrospray Ionization of Sphingomyelins. In The Encyclopedia of Mass Spectrometry, Vol. III. Applications in Biochemistry, Biology, and Medicine, Part A Caprioli, R.; Gross, M. L., Eds.; Elsevier Science: New York, 2005; pp 430-447.

30. Hsu, F. F.; Turk, J. Characterization of Phosphatidylinositol, Phosphatidylinositol-4-Phosphate, and Phosphatidylinositol-4,5-Bisphosphate by Electrospray Ionization Tandem Mass Spectrometry: A Mechanistic Study. J. Am. Soc. Mass Spectrom. 2000, 11, 986-999.

31. Hsu, F. F.; Turk, J. Characterization of Ceramides by Low Energy Collisional-Activated Dissociation Tandem Mass Spectrometry with Negative-Ion Electrospray Ionization. J. Am. Soc. Mass Spectrom. 2002, $13,558-570$.

32. Hsu F. F.; Turk, J. Structural Studies on Phosphatidylserine by Tandem Quadrupole and Multiple Stage Quadrupole Ion-Trap Mass Spectrometry with Electrospray Ionization. J. Am. Soc. Mass Spectrom. 2005, 16, 1510-1522.

33. Zemski Berry, K. A.; Murphy, R. C. Electrospray Ionization Tandem Mass Spectrometry of Glycerophosphoethanolamine Plasmalogen Phospholipids. J. Am. Soc. Mass Spectrom. 2004, 15, 1499-1508.

34. Doering, T. L.; Pessin, M. S.; Hoff, E. F.; Hart, G. W.; Raben, D. M. Englund, P. T. Trypanosome Metabolism of Myristate, the Fatty Acid Required for the Variant Surface Glycoprotein Membrane Anchor. J. Biol. Chem. 1993, 268, 9215-9222. 